Working Copy

DOE/WIPP 02-3183

Revision 1, April 2003

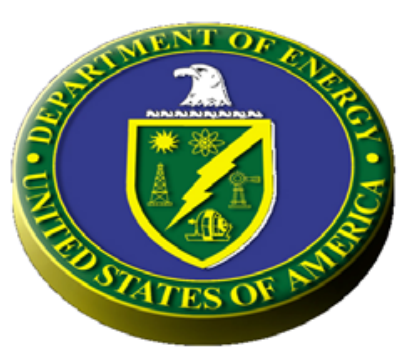

\title{
CH Packaging Program Guidance
}


DOE/WIPP 02-3183

Revision 1, April 2003

\section{CH Packaging Program Guidance}

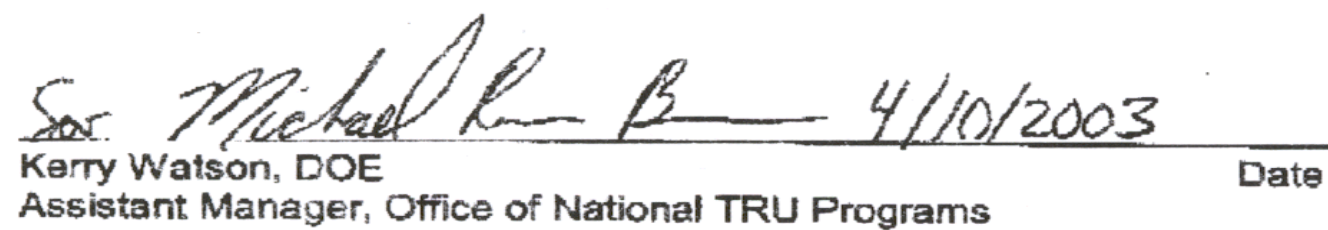

Assistant Manager, Office of National TRU Programs

Processing and final preparation of this paper was performed by Washington TRU Solutions LLC, the Waste Isolation Pilot Plant (WIPP) management and operating (M\&O) contractor under U.S. Department of Energy contract number DE-AC04-01AL66444. 


\title{
Working Copy
}

This document has been submitted as required to:

\author{
Office of Scientific and Technical Information \\ P.O. Box 62 \\ Oak Ridge, TN 37831 \\ (615) $576-8401$
}

Additional information about this document may be obtained by calling (800) 336-9477. Copies may be obtained by contacting the National Technical Information Service, U.S. Department of Commerce, 5285 Port Royal Road, Springfield, VA 22101. 


\section{RECORD OF REVISION}

Revision Reason for Revision/Change

0 New CH Packaging Program Guidance. This document supercedes DOE/WIPP 93-1001 and must be used in conjunction with DOE/WIPP 02-3184, CH Packaging Operations Manual, DOE/WIPP 02-3185, CH Packaging Maintenance Manual, and DOE/WIPP 02-3220, CH Packaging Operations for High Wattage Waste at LANL

1 Revision - A change summary is below:

- Clarify that $C$ of $C$ is the governing document

- Substitute/update e-addresses for mailing addresses

- Retain review and approval for selected actions at CBFO

- Convert some optional (should) actions to mandatory (shall)

- Change part nomenclature for consistency

- Clarify definitions, documentation requirements, and parts listings

- Correct, update, and/or expand parts lists

- Remove superfluous text

- Modify Fig 5.1 to simplify entries 


\begin{tabular}{|c||}
\hline M\&O CONTRACTOR TECHNICAL REVIEW ORGANIZATIONS \\
\hline WASHINGTON TRU SOLUTIONS \\
\hline CBFO REVIEW ORGANIZATIONS \\
NATIONAL TRU PROGRAMS \\
QUALITY ASSURANCE \\
EDITORIAL \\
\hline
\end{tabular}




DOE/WIPP 02-3183 $\quad$ Rev. $1 \quad$ Page 5 of 73

\section{TABLE OF CONTENTS}

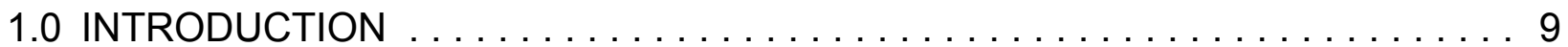

1.1 Purpose .............................. 9

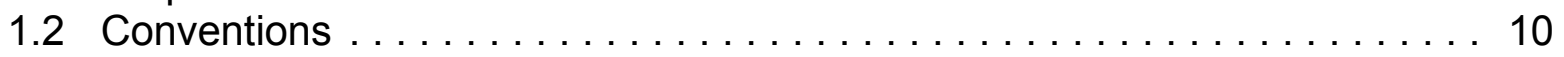

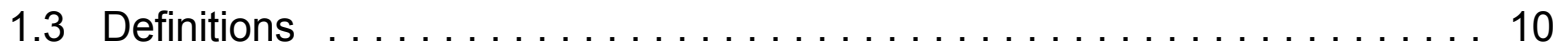

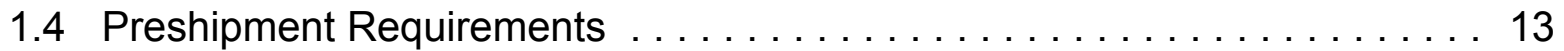

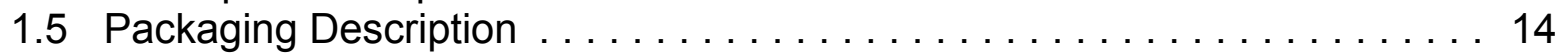

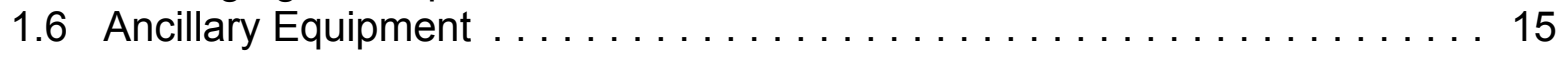

2.0 GENERAL REQUIREMENTS $\ldots \ldots \ldots \ldots \ldots \ldots \ldots \ldots \ldots \ldots \ldots \ldots$

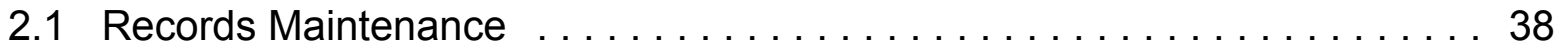

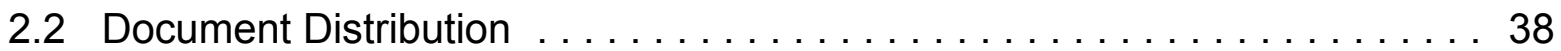

2.3 Approved Work/Periodic Maintenance Instructions . . . . . . . . . 38

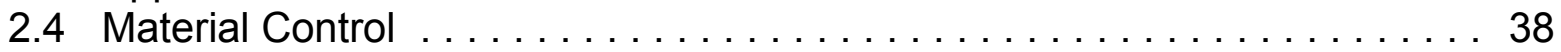

2.5 Quality Assurance Requirements . . . . . . . . . . . . . . . . . . . . . 39

2.6 Training Requirements . . . . . . . . . . . . . . . . . . . . . . . . . . 39

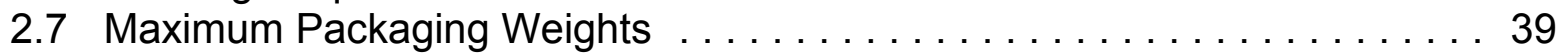

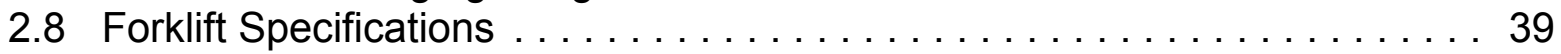

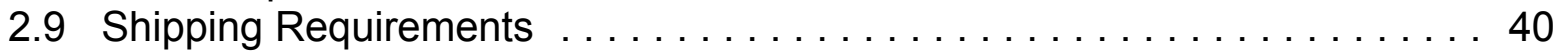

2.10 Shipment Scheduling . . . . . . . . . . . . . . . . . . . . . . 40

2.11 Nonconformance Reports . . . . . . . . . . . . . . . . . 40

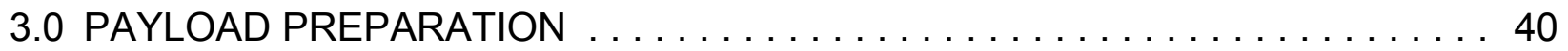

4.0 PACKAGE OPERATING INSTRUCTIONS . . . . . . . . . . . . . . . . . . 40

4.1 General Information on Section $4.0 \ldots \ldots \ldots \ldots \ldots \ldots$

4.2 Operating Tips and Techniques . . . . . . . . . . . . . . . 41

4.2.1 Unloading a Package from a Trailer . . . . . . . . . . . . . . . . . 41

4.2 .2 OCA / ICV Lid Removal . . . . . . . . . . . . . . . . . . . 41

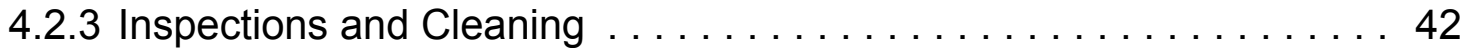

4.2 .4 Loading a Payload . . . . . . . . . . . . . . . . . . . . . 43

4.2 .5 Unloading a Payload . . . . . . . . . . . . . . . . . . . . . 43

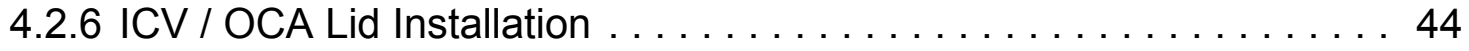

4.2 .7 Loading Packaging onto a Trailer . . . . . . . . . . . . . . . . . . 44

4.2 .8 Lifting a Stuck Lid . . . . . . . . . . . . . . . . . . . . . . . . . . 44

4.3 Notes and Cautions Regarding Operating Instructions . . . . . . . . . 45

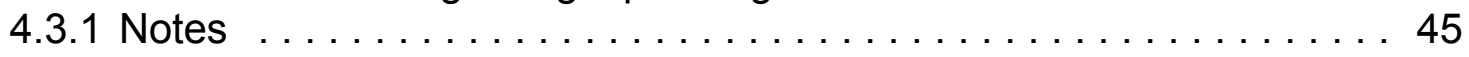

4.3 .2 Cautions . . . . . . . . . . . . . . . . . . . 46

5.0 PACKAGE MAINTENANCE INSTRUCTIONS . . . . . . . . . . . . . . . . 47

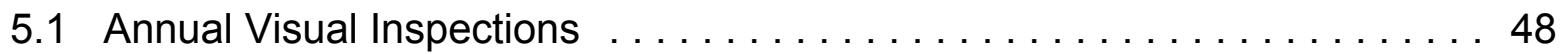

5.2 Annual Dimensional Inspections . . . . . . . . . . . . . . . 48

5.3 Annual ICV Interior Surfaces Inspection $\ldots \ldots \ldots \ldots \ldots \ldots$

5.4 Five-Year Structural Pressure Tests . . . . . . . . . . . . . . . . . . 48

5.5 Packaging Component Replacement Schedule . . . . . . . . . . . . . . . . 48

5.6 Maintenance Records . . . . . . . . . . . . . . . . . . . . . . 49

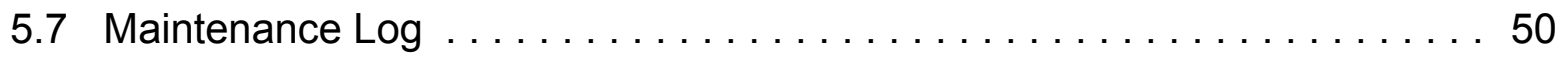

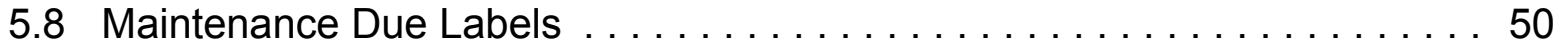




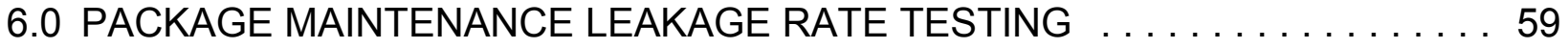

7.0 PACKAGE STRUCTURAL PRESSURE TESTING $\ldots \ldots \ldots \ldots \ldots \ldots \ldots$

Attachment A - Work Instruction Format $\ldots \ldots \ldots \ldots \ldots \ldots \ldots \ldots \ldots \ldots \ldots \ldots$

Attachment B - Approved Work Instructions . . . . . . . . . . . . B - 1

Attachment C - CH Packaging Qualification Requirements $\ldots \ldots \ldots \ldots \ldots$ C - 1 


\section{LIST OF FIGURES}

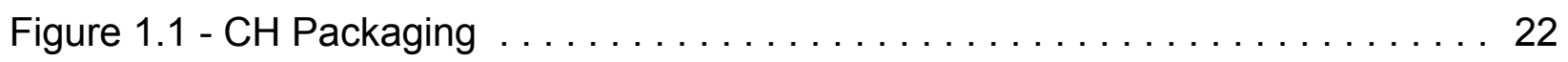

Figure 1.2 - ICV / OCV Vent Port Cover Removal Tool (2077-092-A1) . . . . . . . 23

Figure 1.3 - OCV Vent Port Plug Removal/Pressure Relief Tool (2077-091-A2) . . 24

Figure 1.4 - OCV Leak Detection Tool (2077-095-A1) . . . . . . . . . . . . . 25

Figure 1.5 - OCV Seal Test Port Plug Installation/Removal Tool (2077-094-A1) . . . 26

Figure 1.6 - OCV Seal Leak Check Tool (2077-093-A2) . . . . . . . . . . . 27

Figure 1.7 - ICV Vent Port Plug Removal/Pressure Relief Tool (2077-091-A1) . . . 28

Figure 1.8 - ICV Vent Port Plug Removal/Pressure Relief Tool with Adapter

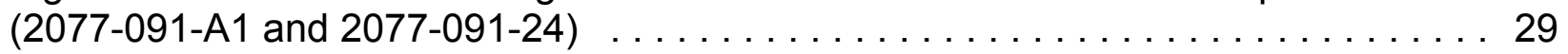

Figure 1.9 - ICV Leak Detection Check Tool (2077-095-A2) . . . . . . . . . . 30

Figure 1.10 - ICV Seal Test Port Plug Installation/Removal Tool (2077-094-A2) . . . 31

Figure 1.11 - ICV Seal Leak Check Tool (2077-093-A1) . . . . . . . . . . . . 32

Figure 1.12 - ICV Components $\ldots \ldots \ldots \ldots \ldots \ldots \ldots \ldots \ldots \ldots \ldots \ldots \ldots \ldots \ldots \ldots \ldots$

Figure 1.13 - OCA / OCV Components ...................... 34

Figure 5.1 - Maintenance Record $\ldots \ldots \ldots \ldots \ldots \ldots \ldots \ldots \ldots \ldots \ldots \ldots \ldots \ldots \ldots \ldots \ldots$ 


\section{LIST OF TABLES}

Table 1.1 - Equipment for Fixed Loading Facility $\ldots \ldots \ldots \ldots \ldots \ldots \ldots \ldots$

Table 1.2 - Recommended User-supplied Tools, Equipment and Consumables . . . 20

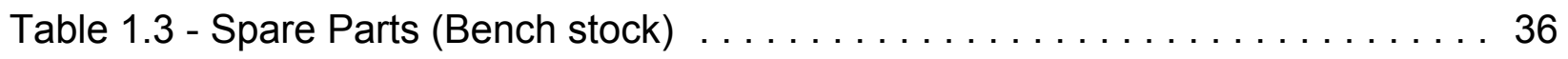

Table 5.1 - ICV Visual Inspections, Acceptance Criteria, and Corrective Action . . . 53

Table 5.2 - OCA Visual Inspections, Acceptance Criteria, and Corrective Action . . . 54

Table 5.3 - Component Inspection, Acceptance Criteria, and Corrective Action . . 57

Table 5.4 - Component Replacement Schedule and Work Instruction . . . . . . . 58 


\section{$1.0 \quad$ INTRODUCTION}

\subsection{Purpose}

The purpose of this document is to provide the technical requirements for preparation for use, operation, inspection, and maintenance of a Transuranic Package Transporter Model II (TRUPACT-II), a HalfPACT shipping package, and directly related components. This document complies with the minimum requirements as specified in the TRUPACT-II Safety Analysis Report for Packaging (SARP), HalfPACT SARP, and Nuclear Regulatory Commission (NRC) Certificates of Compliance (C of C) 9218 and 9279, respectively. In the event of a conflict between this document and the SARP or $C$ of $C$, the $C$ of $C$ shall govern. The $C$ of $C$ s state: "each package must be prepared for shipment and operated in accordance with the procedures described in Chapter 7.0, Operating Procedures, of the application." They further state: "each package must be tested and maintained in accordance with the procedures described in Chapter 8.0, Acceptance Tests and Maintenance Program of the Application." Chapter 9.0 of the SARP charges the WIPP management and operating (M\&O) contractor with assuring packaging is used in accordance with the requirements of the $\mathrm{C}$ of $\mathrm{C}$. Because the packaging is NRC-approved, users need to be familiar with 10 CFR 71.11. Any time a user suspects or has indications that the conditions of approval in the $\mathrm{C}$ of $\mathrm{C}$ were not met, the Carlsbad Field Office (CBFO) shall be notified immediately. CBFO will evaluate the issue and notify the NRC if required.

This document provides the instructions to be followed to operate, maintain, and test the TRUPACT-II and HalfPACT packaging. The intent of these instructions is to standardize operations. All users will follow these instructions or equivalent instructions that assure operations are safe and meet the requirements of the SARPs. Users may achieve this intent by any of the following methods:

- Using these instructions.

- Attaching a site-specific cover page/letter to this document stating that these are the instructions to be used at their location, or

- Preparing their own document using the steps in this document word-for-word, in sequence, including Notes and Cautions. Site-specific information may be included as deemed necessary. The document must then be submitted to Site Documents@wipp.ws for approval. Any revision made subsequent to WIPP approval shall be reviewed and approved by CBFO prior to implementation. A copy of the approval letter from CBFO shall be available for audit purposes.

This document is available on the Internet at:

http://www.wipp.ws/library/t2omi/t2omi.htm. Users are responsible for ensuring they are using the current revision and change notice.

Users may develop site-specific procedures addressing preoperational activities, quality assurance (QA), hoisting and rigging, and radiation health physics to be used in conjunction with the instructions contained in this document. 
Users desiring to recommend changes to this document may submit their recommendations to the WIPP M\&O contractor for evaluation. If approved, the change(s) will be incorporated into this document for use by all users. On an annual basis, not to exceed thirteen months, maintenance and user site's programs will be audited to the requirements contained in this document and any other applicable requirements document.

\subsection{Conventions}

The following conventions are used to standardize the language used in this document:

• $\quad$ The words "will," "shall," and "must" denote requirements.

- The word "should" denotes a recommendation.

- $\quad$ The word "may" denotes permission, neither a requirement nor a recommendation.

- $\quad$ The word "check" is used to determine a condition or status.

- $\quad$ The word "verify" is used to confirm a condition.

- $\quad$ Parts shall be identified with the part number and name as listed in the work instructions $(\mathrm{Wl})$.

- $\quad$ Standard abbreviations (not symbols) will be written out to express measurements and dimensions. For example, use 10 feet or $10 \mathrm{ft}$, but not 10'.

- $\quad$ Acronyms and other abbreviations will be identified fully in the first usage in the instructions.

- $\quad$ Cautions and notes, if used, shall precede the pertinent step(s).

- Cautions and notes shall not be used as instruction steps.

\subsection{Definitions}

- Annual Maintenance - Periodic maintenance that is performed at one-year intervals.

- Bench Stock - The on-hand supply of packaging components sufficient to cover anticipated needs for one calendar year of operation. Stockage levels are based on historical data of component replacement required to complete a given number of shipments.

- $\quad$ Carlsbad Field Office (CBFO) - The U.S. Department of Energy (DOE) office responsible for managing the packaging and transportation activities associated with contact-handled $(\mathrm{CH})$ and remote-handled $(\mathrm{RH})$ transuranic (TRU) materials. 
- $\quad$ Certificate of Compliance (C of $C)$ - A document issued by the NRC, approving the design of a specific radioactive materials packaging for use with specified payload limitations.

- $\quad$ Certified Waste - Waste that has been confirmed under a formal program to comply with acceptance criteria under an approved waste certification program.

- $\quad$ Contact-handled Transuranic (CH TRU) Waste - Waste with an external radiation dose rate not exceeding $200 \mathrm{millirem} / \mathrm{hr}$ at the surface of the waste container. Containers of $\mathrm{CH}$ TRU waste may be handled directly, without the need for remote handling or robotic equipment.

- $\quad$ Five-Year Maintenance - Periodic maintenance that is performed at five-year intervals.

- Inspection/Inspect - Unless otherwise stated in this document, this refers to personnel performing visual examination activities.

- Leak Check Due Tag - A tag attached near the outer containment assembly (OCA) vent port. This tag indicates a containment O-ring has been replaced and a maintenance leakage rate test is required prior to the next use of the packaging for radioactive shipment. The reverse side of the tag will be marked in indelible ink indicating which containment O-ring was replaced.

- $\quad$ Maintenance Leakage Rate Test - This includes leak tests to confirm that maintenance, repair, or component replacement have not degraded the containment system.

- Maintenance Record - A list of maintenance performed that becomes a permanent part of the documentation record.

- Major Maintenance - Consists of all repairs requiring welding or machining to correct a deficiency that affects packaging integrity or components. (Note: major repairs and major component replacements are the responsibility of the WIPP M\&O contractor). These repairs/replacements will be performed at a Maintenance Facility designated and approved by the WIPP M\&O contractor.

- Minor Maintenance - Consists of all repairs that can be readily accomplished and require no special tools, supplies, equipment, or highly skilled personnel. Minor repairs would include scratches on the sealing surface. (Note: minor repairs and minor component replacements shall be performed at sites that have the necessary equipment and qualified personnel to perform these tasks.)

- Mobile Loading Unit (MLU) - This consists of trailer-mounted equipment necessary to load/unload packaging at locations where fixed loading/unloading facilities do not exist.

- Nonconformance Report (NCR) - A document that identifies and records a nonconforming condition, and the action taken for the disposition of the 
nonconformance. Disposition of nonconforming items include review, accept, reject, rework, use-as-is, or repair in accordance with approved instructions. All occurrences of NCRs require formal disposition by the WIPP M\&O contractor.

- Nuclear Regulatory Commission (NRC) - The federal agency that certifies the design, manufacture, and QA of TRU materials shipment packaging by certifying that all packaging meets the design requirements specified in 10 Code of Federal Regulations (CFR) Part 71.

- Out-of-Service - An administrative condition of the packaging that denotes it is not useable for radioactive shipments. When a packaging is determined to be out-of-service, a tag shall be attached to the OCA near the vent port. The tag shall state the out-of-service condition.

- $\quad$ Owner - The organization to which the NRC C of $C$ is issued (e.g., for DOE TRUPACT-II and HalfPACT shipping packages).

- $\quad$ Package - Package means a Type B packaging together with its radioactive contents.

- $\quad$ Packaging - Packaging means the assembly of components necessary to ensure compliance with the packaging requirements of 10 CFR 71.

- $\quad$ Periodic Leakage Rate Test - This test includes leak tests to verify containment boundary integrity.

- $\quad$ Periodic Maintenance (PM) - This consists of all maintenance activities performed annually or at other periodic time intervals. Periodic maintenance activities listed in Section 5.0 will normally be performed at a maintenance facility designated and approved by the WIPP M\&O contractor.

- $\quad$ Preshipment Leakage Rate Test - This test includes all leak tests performed during assembly of a loaded package.

- $\quad$ Safety Analysis Report for Packaging (SARP) - The official application to a packaging licensing agency (DOE or NRC) containing a demonstration of packaging effectiveness and ability to achieve the requirements delineated in 10 CFR 71. The SARP is the controlling document for all packaging operations and maintenance.

- $\quad$ Test and Handling (T\&H) Equipment - Equipment required to be on hand to load, unload, and test the packaging.

- Transuranic Content Codes (TRUCON) - A uniform system grouping waste forms with similar characteristics for purposes of shipment in the packaging. 
- $\quad$ Transuranic (TRU) Waste - Waste containing more than 100 nanocuries of alpha-emitting transuranic isotopes per gram of waste, with half-lives greater than 20 years, except for:

- High-level radioactive waste

- Waste that the Secretary has determined, with concurrence of the Administrator, does not need the degree of isolation required by the disposal regulations

- Waste that the NRC has approved for disposal on a case-by-case basis in accordance with 10 CFR 61.

- $\quad$ Transuranic Waste Authorized Methods for Payload Control (TRAMPAC) The document that provides acceptable methods of preparation and characterization to qualify TRU waste as a payload for transport in the packaging.

- Users - Those organizations, both DOE and commercial, that are authorized by the DOE to use the DOE-owned, NRC-approved packaging to ship or receive waste.

- Visual Inspection - An inspection of component attributes, usually performed using a checklist.

- $\quad$ WIPP - The Waste Isolation Pilot Plant.

- Work Instruction - A form containing detailed steps outlining the requirements for performing maintenance activities.

- Work Control - The process by which all scheduled and unscheduled maintenance is initiated, prioritized, performed, and documented.

\section{$1.4 \quad$ Preshipment Requirements}

Prior to making the initial shipment of TRU waste, the user must submit $\mathrm{CH}$ Packaging Authorized Methods for Payload Control (TRAMPAC), operating and handling procedures, leak test procedures, and associated QA plans to CBFO for review and approval. If needed, additional guidance for these areas may be obtained by contacting the WIPP M\&O contractor. A new user must also perform the following:

- Determine whether a fixed facility or a mobile loading unit will be required. The facility must meet minimum size and height requirements to accommodate loading operations. Minimum electrical power requirements for operation of a crane and other equipment must be considered.

- $\quad$ Obtain the T\&H equipment (see Table 1.1). 
- Obtain the consumables and bench stock of spare parts (see Table 1.2 and Table 1.3).

- $\quad$ Prepare and approve site procedures (QA, hoisting and rigging, preoperational, and radiation health physics) for use during packaging operations.

- Obtain authorization to use, and complete training to operate the DOE TRANSCOM satellite-based shipment tracking system.

- $\quad$ Complete training and site-specific qualification of personnel to perform packaging operations.

- $\quad$ Successfully complete a certification audit by CBFO/WIPP contractor to ship TRU waste in $\mathrm{CH}$ packaging. Certification will include observation of a DUMMY loading operation and performance of randomly selected Maintenance Instructions, to include preparation of associated documentation. (This does not apply to small-quantity sites with shipments loaded by other trained personnel.)

\subsection{Packaging Description}

The TRUPACT-II and HalfPACT are U.S. Department of Transportation (DOT) Type "B" packagings certified by the NRC. Both are stainless steel and polyurethane foam insulated right circular cylinder shipping containers. They are designed to provide double containment for shipment of CH TRU waste.

A list of authorized payload containers is found in DOE/WIPP 02-3122, Waste Acceptance Criteria (WAC) for the Waste Isolation Pilot Plant (latest revision).

The outer containment assembly (OCA) consists of a lid and body, composed of an inner stainless steel shell which comprises the outer containment vessel (OCV) boundary, about ten inches of thermal and impact absorbing polyurethane foam, and an external stainless steel shell. The lid's internal and external surfaces are domed. The body internal surface bottom is domed and the external surface bottom is flat. Three lifting interfaces are supplied on the lid. Two forklift slots in the body base are used for handling the entire loaded OCA. When the lid is installed on the body, the overall height is about 10 feet and overall diameter is about 8 feet. A tapered sealing flange on the lid mates with a similar sealing flange on the body. The body sealing flange contains two main O-ring seals. A removable brass plug in a seal test port allows testing of the upper main O-ring seal. The lid is secured to the body with a rotating locking ring located on the lid sealing flange. Six fasteners secure the locking ring from rotating during shipment. A single vent port comprises the only containment penetration into the OCV cavity. A removable brass plug in the vent port allows access to the cavity.

The inner containment vessel (ICV) consists of a stainless steel shell lid and body. Both the lid and body ends are domed to mate with the interior cavity of the OCV. Three lifting sockets in the lid provide the lifting interface for the lid or an empty (contents not installed) lid/body assembly. Aluminum honeycomb spacers inside the lid and body domes provide impact protection to the domes and a flat surface on which the packaging contents are installed. A tapered sealing flange on the lid mates with a 
similar sealing flange on the body. The body sealing flange contains two main O-ring seals. Both a silicone-debris shield and an O-ring wiper seal are contained on the lid sealing flange to preclude debris ingress into the main O-ring seal area. A removable brass plug in a seal test port allows testing of the upper main O-ring seal. The lid is secured to the body by a rotating locking ring located on the lid sealing flange. Three fasteners secure the locking ring from rotating during shipment. A single vent port comprises the only containment penetration into the ICV cavity. A removable inner brass plug in the vent port allows access to the ICV cavity. A removable outer brass plug in the vent port allows for helium purging of the ICV upper main O-ring seal and the volume between the inner and outer plug for subsequent leakage testing.

\subsection{Ancillary Equipment}

\subsubsection{Seal Test Port and Vent Port Tools}

Seal test port and vent port tools are provided by the WIPP M\&O contractor as indicated in Table 1.1. Quantities are sufficient for user site requirements with provisions for a limited number of spares. Before use, tools should be inspected for thread and O-ring damage as well as galling of moving parts. Replacement O-rings are as specified on the figures illustrating each tool and are also listed in Table 1.2. Replacements for defective tools are provided by the WIPP M\&O contractor $\mathrm{CH}$ Packaging Maintenance Engineer on an exchange basis.

Several tools have been designed specifically for the operation and leakage-rate testing of the shipping package. Although the OCV and ICV seal test ports and vent ports are similar in design, the tools are not interchangeable.

The functional description of each tool is as follows:

- $\quad$ OCV seal test port plug installation/removal tool provides for installation and removal of the OCV seal test port plug through the seal test access port in the OCA upper assembly (see Figure 1.5, Part No. 2077-094-A1).

- $\quad$ OCV seal leak check tool is used to check the main O-ring seal for leakage (see Figure 1.6, Part No. 2077-093-A2). Access is through the seal test access port in the OCA upper assembly. This tool is equipped with a quick-connect fitting to interface with the leak-testing equipment.

- $\quad$ ICV/OCV vent port cover removal tool provides for remote removal and installation of the vent port covers (see Figure 1.2, Part No. 2077-092-A1).

- $\quad$ OCV vent port plug removal/pressure relief tool provides for the removal and installation of the OCV vent port plug, and access to the OCV cavity through the vent access port in the OCA lower assembly (see Figure 1.3, Part 
No. 2077-091-A2). This tool is equipped with a quick-connect fitting to interface with sampling, vacuum, and helium backfill equipment and is used for the following operations:

- OCV annulus venting and sampling

- Vacuum pump interface for OCA upper assembly installation and removal

- Helium backfill during OCV leakage testing

- Pressure fill during periodic OCV structural pressure-testing and axial play measurements.

- $\quad$ OCV leak detection tool is used to check the OCV vent port plug seal for leakage tests (see Figure 1.4, Part No. 2077-095-A1). Access is through the vent access port in the OCA lower assembly. This tool is equipped with a quickconnect fitting to interface with the leak-testing equipment.

- $\quad$ ICV vent port plug removal/pressure relief tool provides for the removal and installation of the ICV outer vent port plug (see Figure 1.7, Part No. 2077-091-A1), removal and installation of the ICV inner vent port plug, with an adapter (see Figure 1.8, Part No. 2077-091-24), thereby gaining access to the ICV cavity. This tool is equipped with a quick-connect fitting to interface with sampling, vacuum, and helium backfill equipment and is used for the following operations:

- ICV cavity venting and sampling (with the adapter),

- Vacuum pump interface for ICV lid installation and removal,

- Helium backfill during ICV leakage testing, and

- Pressure fill during periodic ICV structural pressure testing and axial play measurements.

- $\quad$ ICV leak detection tool is used to check the ICV vent port plug seal for leakage (see Figure 1.9, Part No. 2077-095-A2). This tool is equipped with a quickconnect fitting to interface with the leak-testing equipment.

- $\quad$ ICV seal test port plug installation/removal tool provides for installation and removal of the ICV seal test port plug (see Figure 1.10, Part No. 2077-094-A2).

- $\quad$ ICV seal leak check tool is used to check the main O-ring seal for leakage (see Figure 1.11, Part No. 2077-093-A1). This tool is equipped with a quick-connect fitting to interface with the leak-testing equipment. 


\subsubsection{Lock-Ring Tools}

The locking ring tools are designed for rotating the locking ring assemblies to either the locked or unlocked position.

NOTE: Lock-ring tools are furnished by the WIPP.

\subsubsection{Lower Spacer Removal Sling}

The lower spacer removal sling is designed for installation and removal of the lower spacer (Part No. SK-1104).

\subsubsection{Adjustable Center of Gravity Lift Fixture (ACGLF)}

NOTE: Users are responsible for procurement and maintenance of an ACGLF. Drawings for the Standard Waste Box (SWB), ACGLF, and Ten-Drum Overpack (TDOP) adapters are available from the WIPP.

The ACGLF is used for loading and unloading payloads when the center of gravity is not on the vertical centerline of the payload. With an adaptor, the ACGLF may be used for loading and unloading SWBs and TDOPs.

The ACGLF is used in conjunction with a 5-ton crane (minimum) and is designed for the following general requirements:

- Maximum rated capacity of the lift fixture is $10,000 \mathrm{lb}$.

- $\quad$ System power is $115 \mathrm{VAC}, 60 \mathrm{~Hz}, 20$ amperes.

- Minimum crane hook height is $20.5 \mathrm{ft}$.

- $\quad$ Maximum 7.5-ton Crosby hook size interface.

- $\quad$ One 14-drum payload assembly, two SWB payload assemblies, or one TDOP may be lifted at one time; and

- A 3.6-inch maximum lateral offset in the payload assembly center of gravity may be accommodated.

The ACGLF is designed to handle the weight of the following configurations:

- $\quad$ An OCA lid assembly

- $\quad$ An ICV lid

- $\quad$ An empty ICV assembly

- A payload (i.e., 14 drums), two SWBs, or one TDOP 
The ACGLF is NOT designed to lift the weight of the following configurations:

- $\quad$ A loaded $\mathrm{CH}$ package or empty $\mathrm{CH}$ packaging

- A loaded or empty OCA

- $\quad$ A loaded ICV

1.6.5 Tools, Equipment, and Consumables for $\mathrm{CH}$ Packaging Loading

Table 1.1 lists the tools required for packaging operations. Quantities listed are for a fixed facility with a limited number of spares. Specifically designed tools (i.e., leak check, leak detection, and pressure relief) are provided by the WIPP through the $\mathrm{CH}$ Packaging Maintenance Engineer. 


\section{Table 1.1 - Equipment for Fixed Loading Facility}

\begin{tabular}{|c|c|c|c|}
\hline Tool & Quantity & Spares & $\checkmark$ \\
\hline $\begin{array}{l}\text { ICV/OCV vent port cover removal tool } \\
\text { (2077-092-A1), (Figure 1.2) }\end{array}$ & $\begin{array}{l}1 \\
\text { common hand tool } \\
\text { (user-supplied) }\end{array}$ & 0 & \\
\hline $\begin{array}{l}\text { OCV vent port plug removal/pressure relief tool } \\
\text { (2077-091-A2), (Figure 1.3) }\end{array}$ & 3 & 1 & \\
\hline OCV leak detection tool (2077-095-A1), (Figure 1.4) & 3 & 1 & \\
\hline $\begin{array}{l}\text { OCV seal test port plug installation/removal tool } \\
\text { (2077-094-A1), (Figure 1.5) }\end{array}$ & $\begin{array}{l}1 \\
\text { common hand tool } \\
\text { (user-supplied) }\end{array}$ & 0 & \\
\hline $\begin{array}{l}\text { OCV seal leak check tool (2077-093-A2), } \\
\text { (Figure 1.6) }\end{array}$ & 3 & 1 & \\
\hline $\begin{array}{l}\text { ICV vent port plug removal/pressure relief tool and } \\
\text { adapter (2077-091-A1 and 2077-091-24), (Figure } 1.7 \\
\text { and 1.8). }\end{array}$ & 3 & 1 & \\
\hline ICV leak detection tool (2077-095-A2) (Figure 1.9) & 3 & 1 & \\
\hline $\begin{array}{l}\text { ICV seal test port plug installation/removal tool } \\
(2077-094-A 2) \text { (Figure 1.10) }\end{array}$ & $\begin{array}{l}1 \\
\text { common hand tool } \\
\text { (user-supplied) }\end{array}$ & 0 & \\
\hline $\begin{array}{l}\text { ICV seal leak check tool (2077-093-A1) } \\
\text { (Figure 1.11) }\end{array}$ & 3 & 1 & \\
\hline ICV locking handle (2077-156A6) & 6 & 1 & \\
\hline OCV locking handle (2077-156A7) & 6 & 1 & \\
\hline Helium leak detector & 1 (user-supplied) & Optional & \\
\hline Calibrated leak standard & 1 (user-supplied) & Optional & \\
\hline Calibrated barometer & 1 (user-supplied) & Optional & \\
\hline Calibrated ambient temperature measuring device & 1 (user-supplied) & Optional & \\
\hline Tool, locking ring & 2 per site & None & \\
\hline Parts shadow board & $\begin{array}{l}1 \text { per loading } \\
\text { station }\end{array}$ & None & \\
\hline Calibrated crane load cell & 1 per crane & 1 & \\
\hline
\end{tabular}


DOE/WIPP 02-3183

Rev. 1

Page 20 of 73

Table 1.2 - Recommended User-supplied Tools, Equipment and Consumables

\begin{tabular}{|c|c|c|}
\hline Item & Application & $\checkmark$ \\
\hline Compressed-air blow gun & $\begin{array}{l}\text { Clean threads, cavities with } \\
\text { Argon gas }\end{array}$ & \\
\hline 12-inch adjustable wrench $\times 2$ & $\begin{array}{l}\text { Fastening gauges to } \\
\text { compressed gases }\end{array}$ & \\
\hline $\begin{array}{l}\text { 3/4-inch deep-well socket, } 1 / 2 \text {-inch ratchet drive } \\
16 \text { inches or longer }\end{array}$ & Loosening tie-downs & \\
\hline 1/4-inch flat tip screwdriver & $\begin{array}{l}\text { Hose clamps on leak test } \\
\text { equipment and forklift pocket } \\
\text { cover screws }\end{array}$ & \\
\hline $\begin{array}{l}\text { Calibrated Torque wrenches, range } 55-65 \mathrm{lb} \text {-in / } \\
30-50 \mathrm{lb} \text {-ft }\end{array}$ & Torque components & \\
\hline Cotter pin removal tool & Removing small O-rings & \\
\hline Utility knife & Cutting tube for leak testing & \\
\hline Small flashlight & $\begin{array}{l}\text { Inspection of threads and } \\
\text { cavities }\end{array}$ & \\
\hline $\begin{array}{l}\text { Wire brushes, flat and } 1 / 2,3 / 4,1,1-1 / 4 \text { and } \\
\text { 1-1/2-inch sizes SS }\end{array}$ & $\begin{array}{l}\text { Cleaning threads on plugs } \\
\text { and ports }\end{array}$ & \\
\hline $\begin{array}{l}\text { 3/8-inch T-handle Allen wrench } \times 2 \text {, 3/8-inch Allen } \\
\text { head socket with } 3 / 8 \text {-inch drive }\end{array}$ & Removing locking ring bolts & \\
\hline Lint-free rags & $\begin{array}{l}\text { Cleaning surfaces as } \\
\text { required }\end{array}$ & \\
\hline $\begin{array}{l}\text { 1-inch Allen wrench, 1-inch Allen head socket with } \\
\text { 3/8-inch drive }\end{array}$ & Remove/install plugs & \\
\hline Spray bottle (1 quart) & $\begin{array}{l}\text { Applying alcohol when } \\
\text { cleaning surfaces }\end{array}$ & \\
\hline Argon & Purge gas & \\
\hline Nitrogen/compressed air & Lid removal & \\
\hline Helium (welding grade) & Leak testing & \\
\hline Vacuum grease & Lubricate O-rings & \\
\hline Thread-locking compound (Locktite 222) & Threaded surfaces & \\
\hline Nickel-bearing lubricant & Threaded surfaces & \\
\hline Alcohol, denatured & Cleaning surfaces & \\
\hline Stretch wrap, 60 -gauge, up to 22 -inch & Wrap drum payload & \\
\hline
\end{tabular}


Table 1.2 - Recommended User-supplied Tools, Equipment and Consumables

\begin{tabular}{||l|l|c||}
\hline \hline \multicolumn{1}{|c|}{ Item } & \multicolumn{1}{|c||}{ Application } & $\checkmark$ \\
\hline \hline $\begin{array}{l}\text { O-rings (National, Buna-N, \#AS-568-914, } \\
\text { \#AS-568-912, \#AS-568-916, and \#AS-568-015, } \\
\text { and Parker, Buna-N, \#3-905, 10 ea. suggested) }\end{array}$ & $\begin{array}{l}\text { Leak/Seal Check/Detection } \\
\text { Tools }\end{array}$ & \\
\hline $\begin{array}{l}\text { Keensert installation tools (PN TD-420L and } \\
\text { PN TD-813L) }\end{array}$ & $\begin{array}{l}\text { Locking ring bolt insert thread } \\
\text { repair }\end{array}$ & \\
\hline Rubber gloves & Cleaning & \\
\hline $\begin{array}{l}\text { Load-stabilizing jack (McMaster-Carr \#8817T21 or } \\
\text { equivalent) }\end{array}$ & Stabilize freestanding trailers & \\
\hline $\begin{array}{l}\text { Tamper seal (American Casting and Manufacturing } \\
\text { Corp., 51 Commercial Street, Plainview, NY } \\
11803,516-349-7010)\end{array}$ & Seal package for shipment & \\
\hline $\begin{array}{l}\text { Standard Waste Boxes, Ten-Drum Overpacks, and } \\
\text { pipe components may be procured through the } \\
\text { WIPP Centralized Procurement Program. Pipe } \\
\text { components must meet the requirements of the } \\
10 \text { CFR 71 QA program. Vendor qualifications } \\
\text { should be reviewed prior to placing orders. }\end{array}$ & Payloads & \\
\hline
\end{tabular}


Figure 1.1 - $\mathrm{CH}$ Packaging

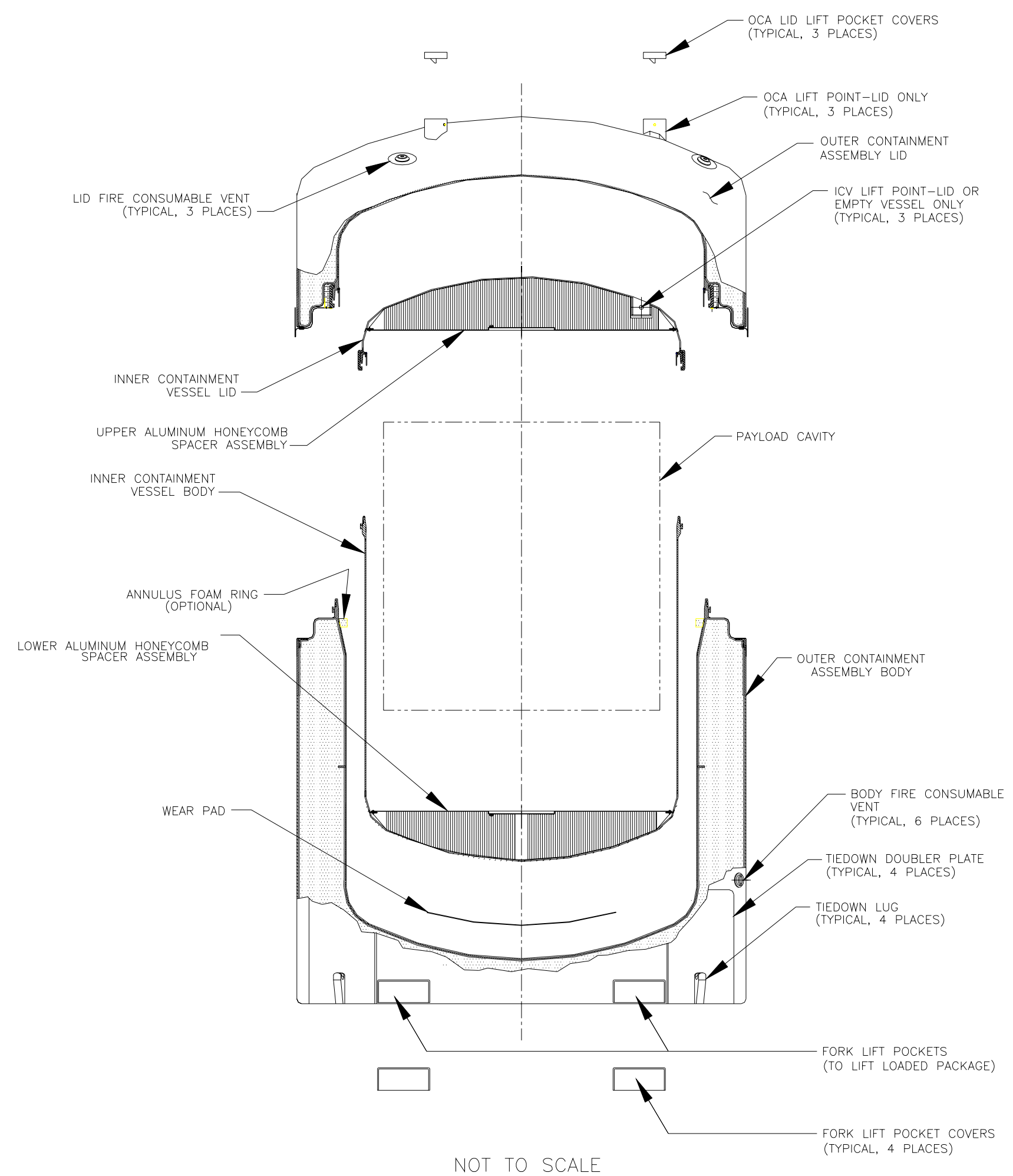


Figure 1.2 - ICV / OCV Vent Port Cover Removal Tool (2077-092-A1)

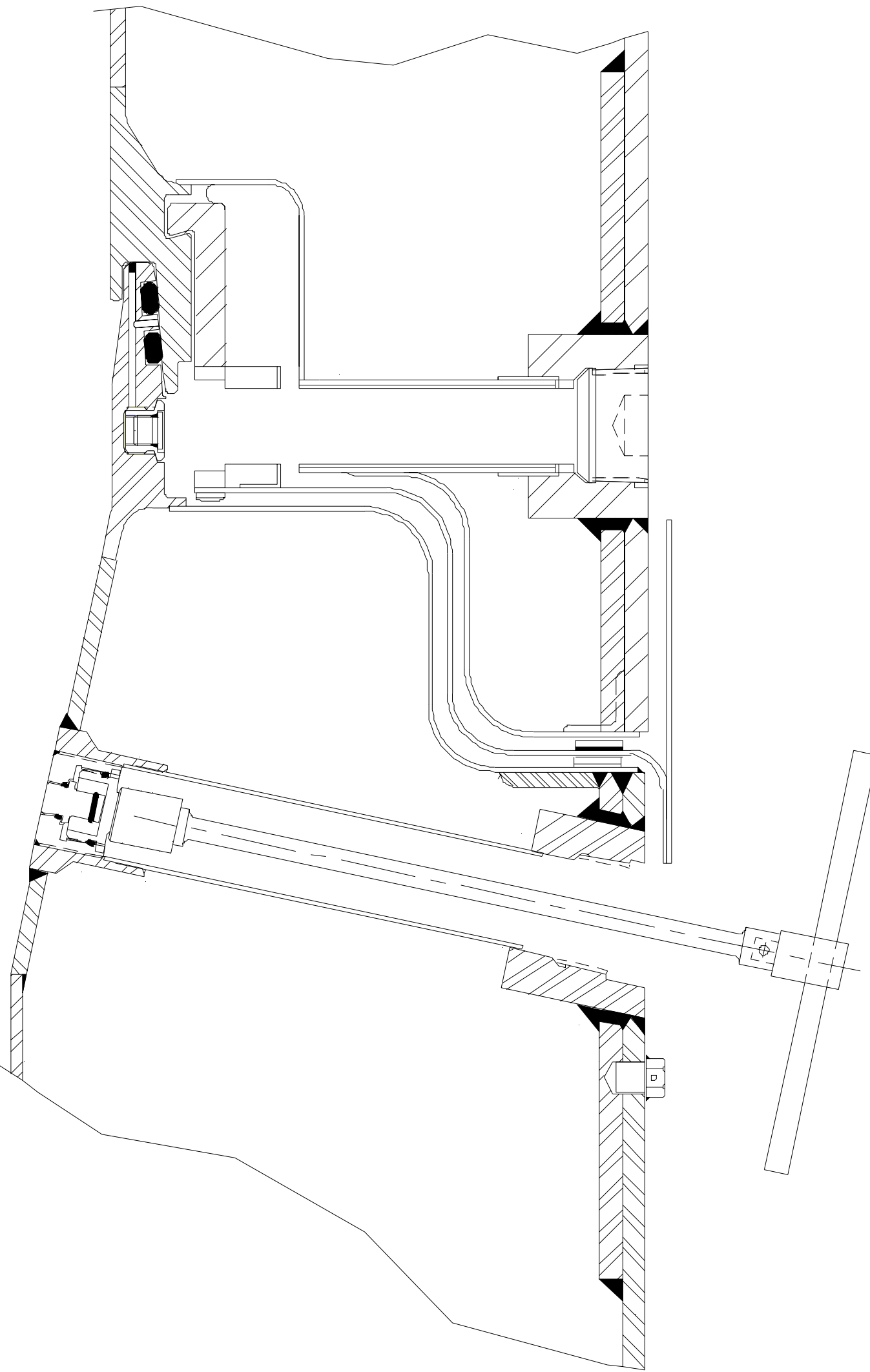

Not to scale 
Figure 1.3 - OCV Vent Port Plug Removal/Pressure Relief Tool (2077-091-A2)

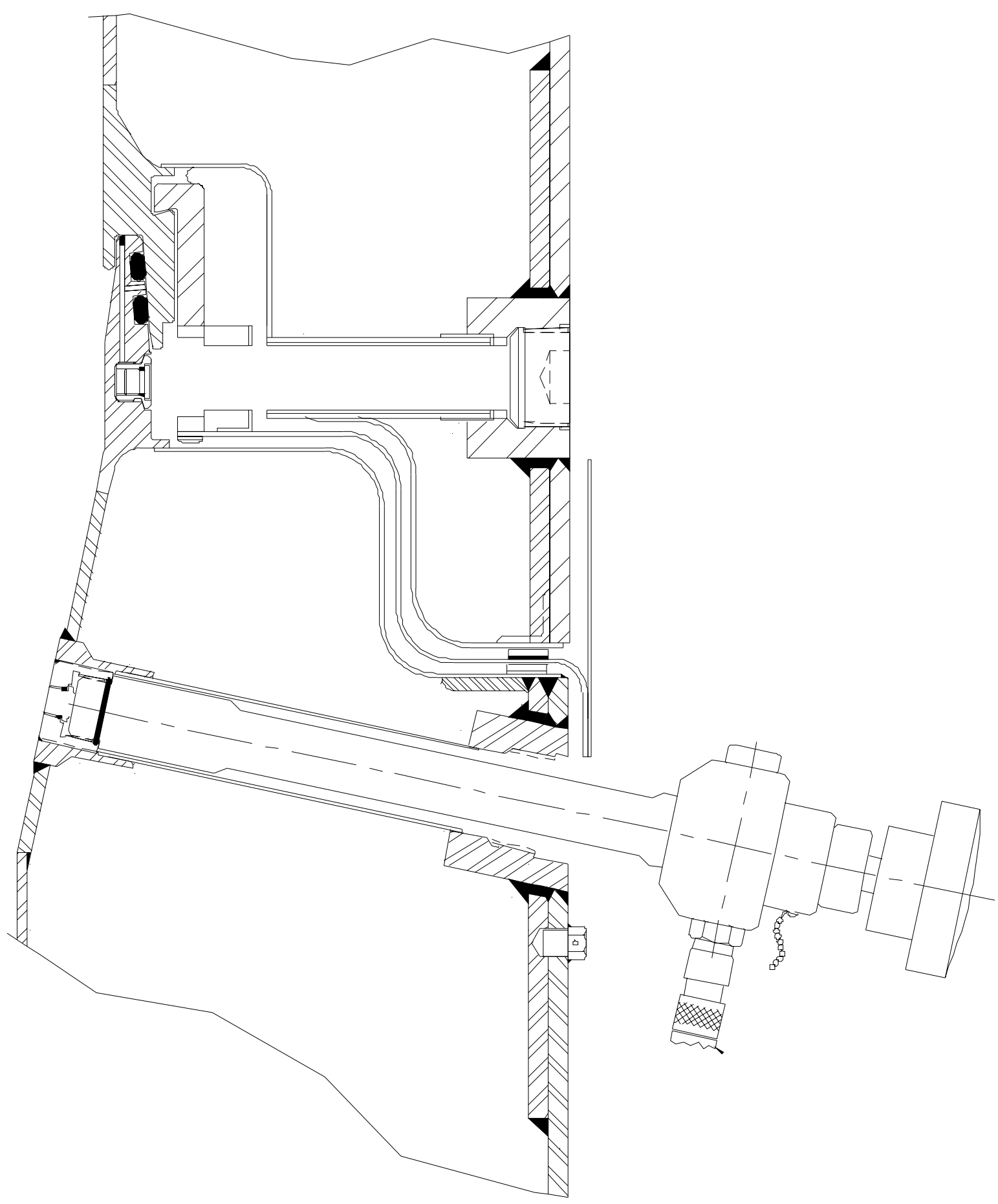

Not to scale

Note: Uses National O-ring, Buna N, Part \#AS-568-914, \#AS-568-912, and \#AS-568-015 
Figure 1.4 - OCV Leak Detection Tool (2077-095-A1)

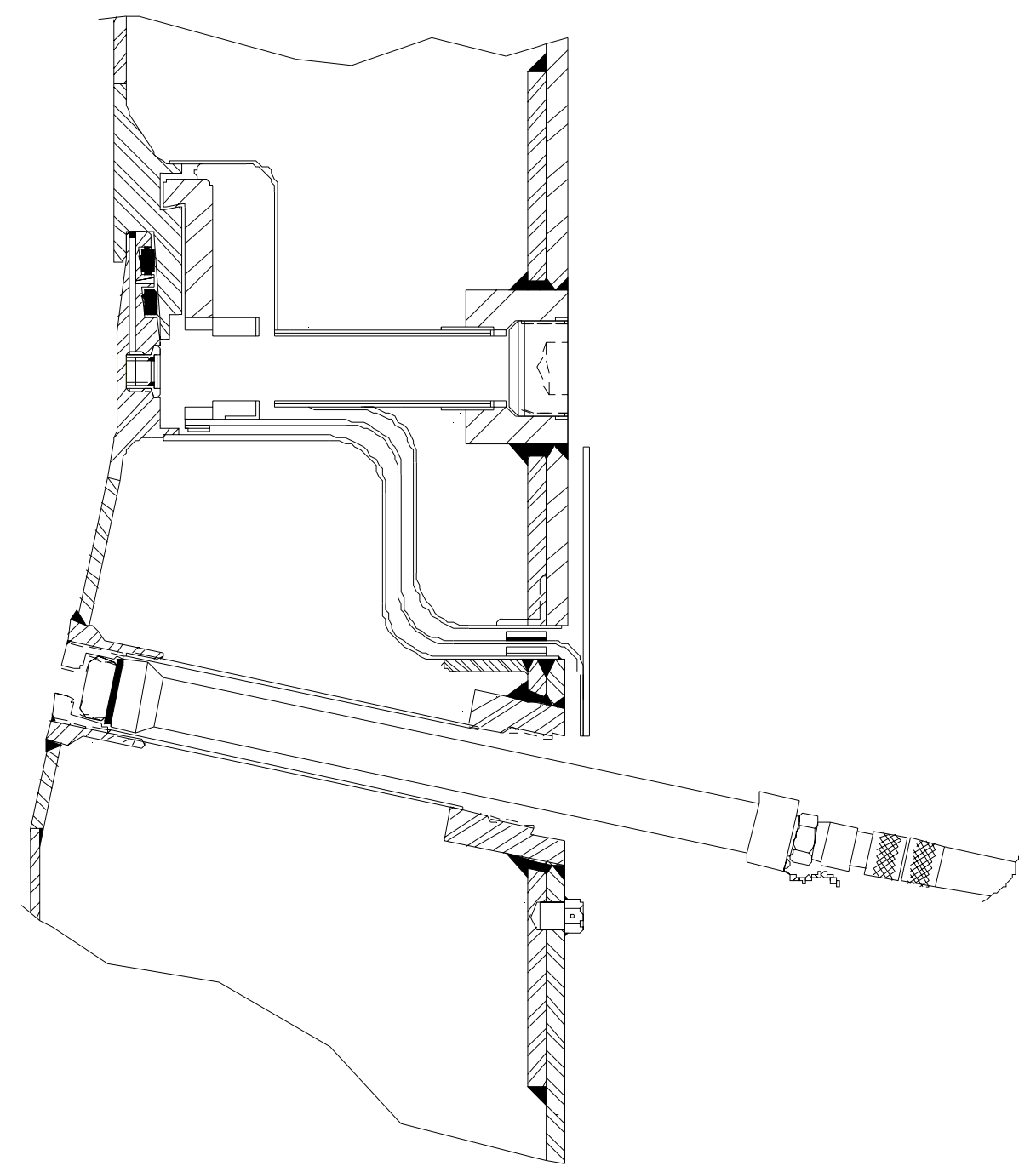

Not to scale

Note: Uses National O-ring, Buna N, Part \# AS-568-914 
Figure 1.5 - OCV Seal Test Port Plug Installation/Removal Tool (2077-094-A1)

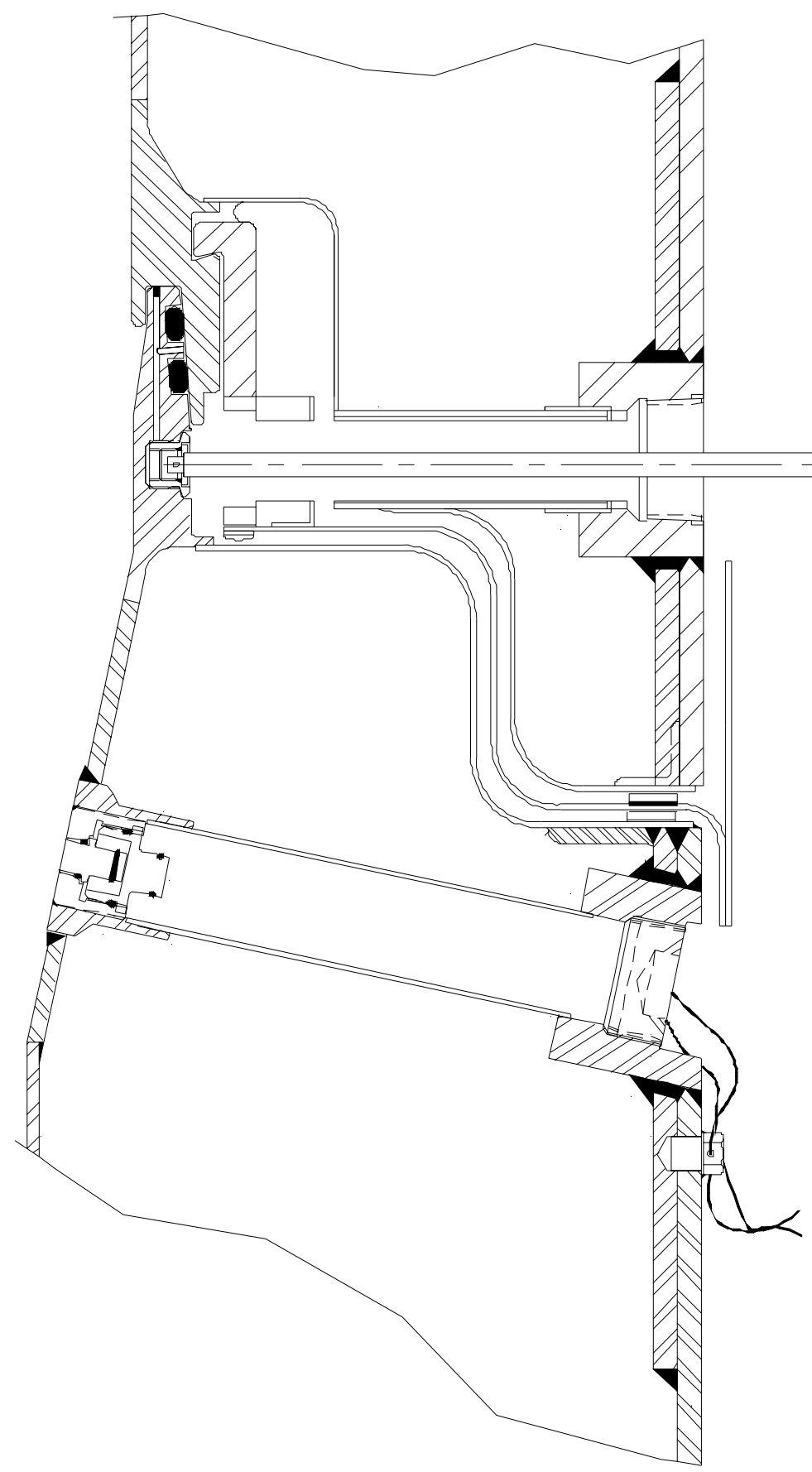

Not to scale 
Figure 1.6 - OCV Seal Leak Check Tool (2077-093-A2)

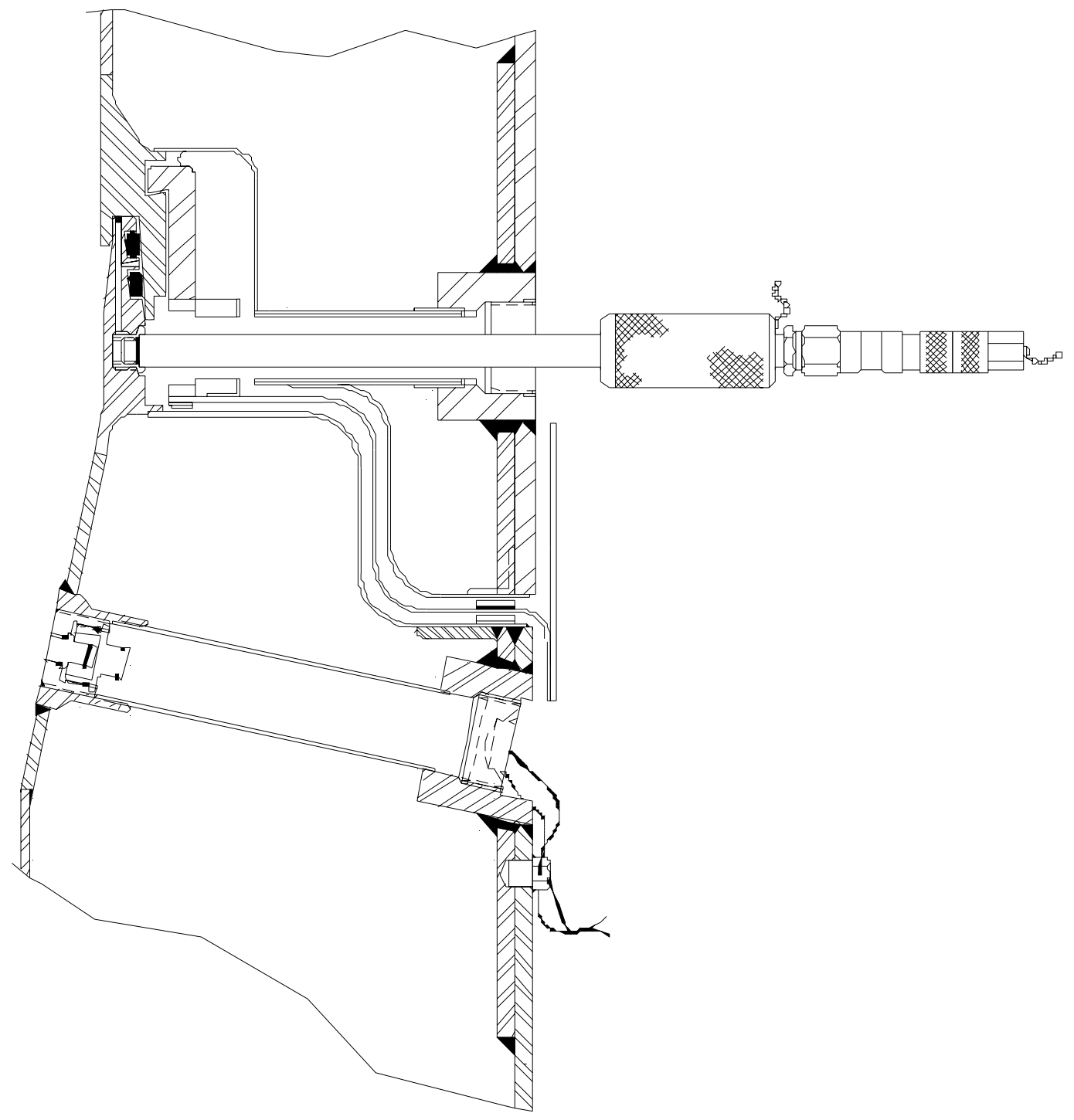

Not to scale

Note: Uses Parker O-ring, Buna N, Part \# 3-905 
Figure 1.7 - ICV Vent Port Plug Removal/Pressure Relief Tool (2077-091-A1)

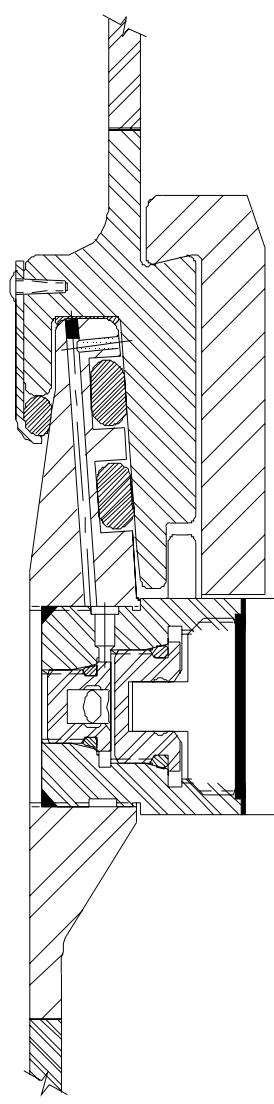

Not to scale

Note: Uses National O-ring, Buna-N, Part \# AS-568-916 and \# AS-568-015 
Figure 1.8 - ICV Vent Port Plug Removal/Pressure Relief Tool with Adapter (2077-091-A1 and 2077-091-24)

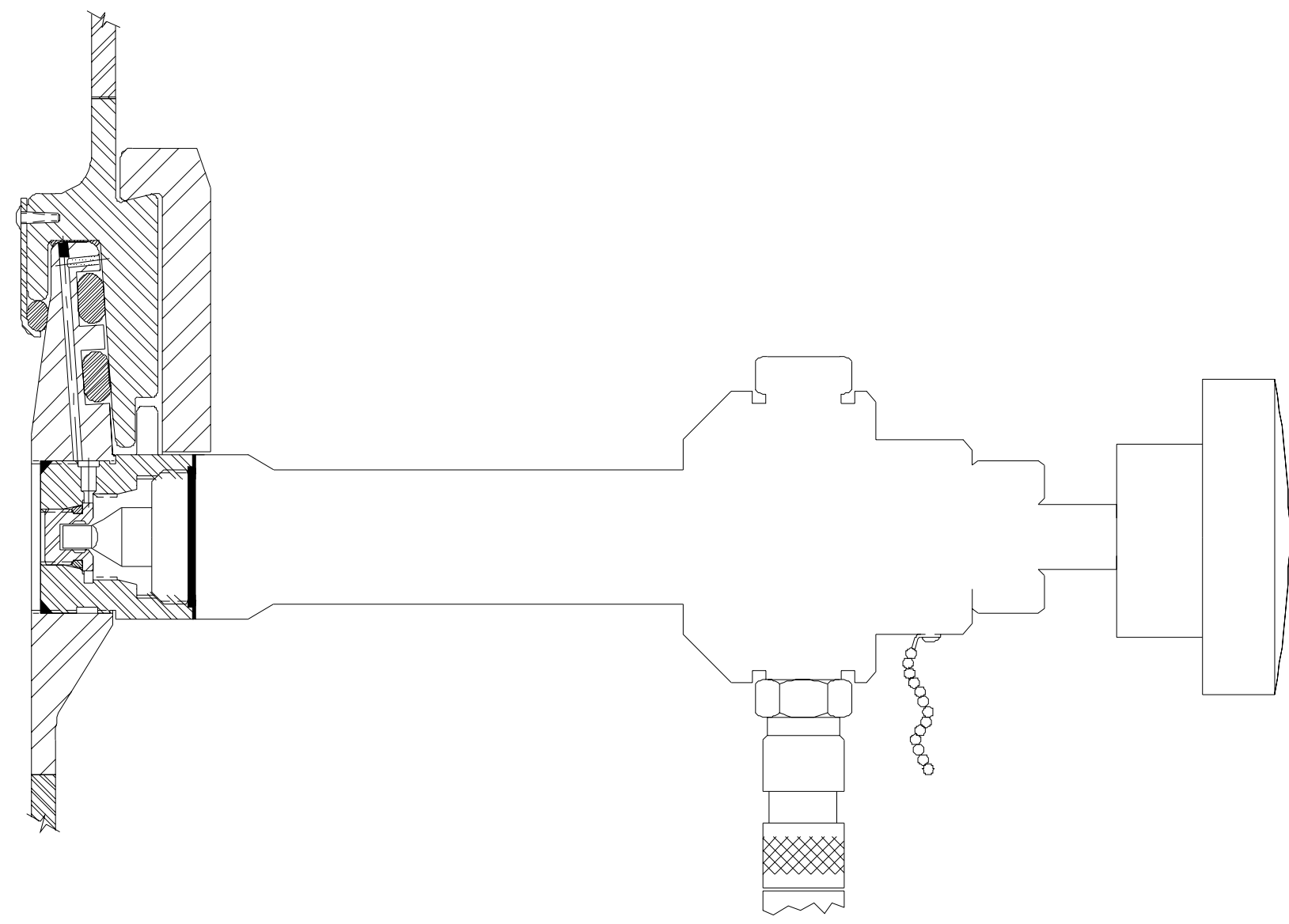

Not to scale

Note: Uses National O-ring, Buna-N, Part \#AS-568-916, \#AS-568-914 and \#AS-568-015 
Figure 1.9 - ICV Leak Detection Tool (2077-095-A2)

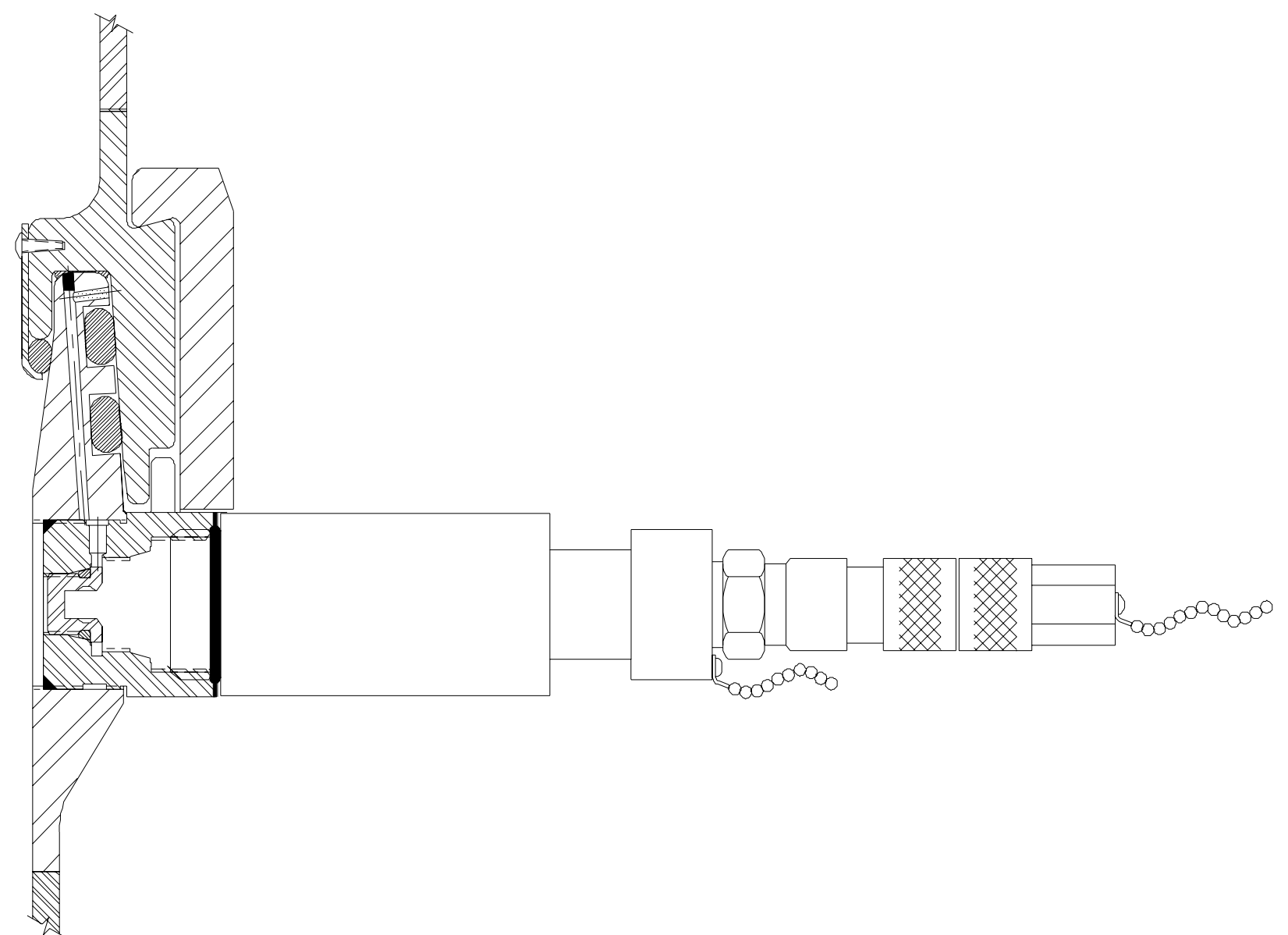

Not to scale

Note: Uses National O-ring, Buna-N, Part \# AS-568-916 
Figure 1.10 - ICV Seal Test Port Plug Installation/Removal Tool (2077-094-A2)

Not to scale

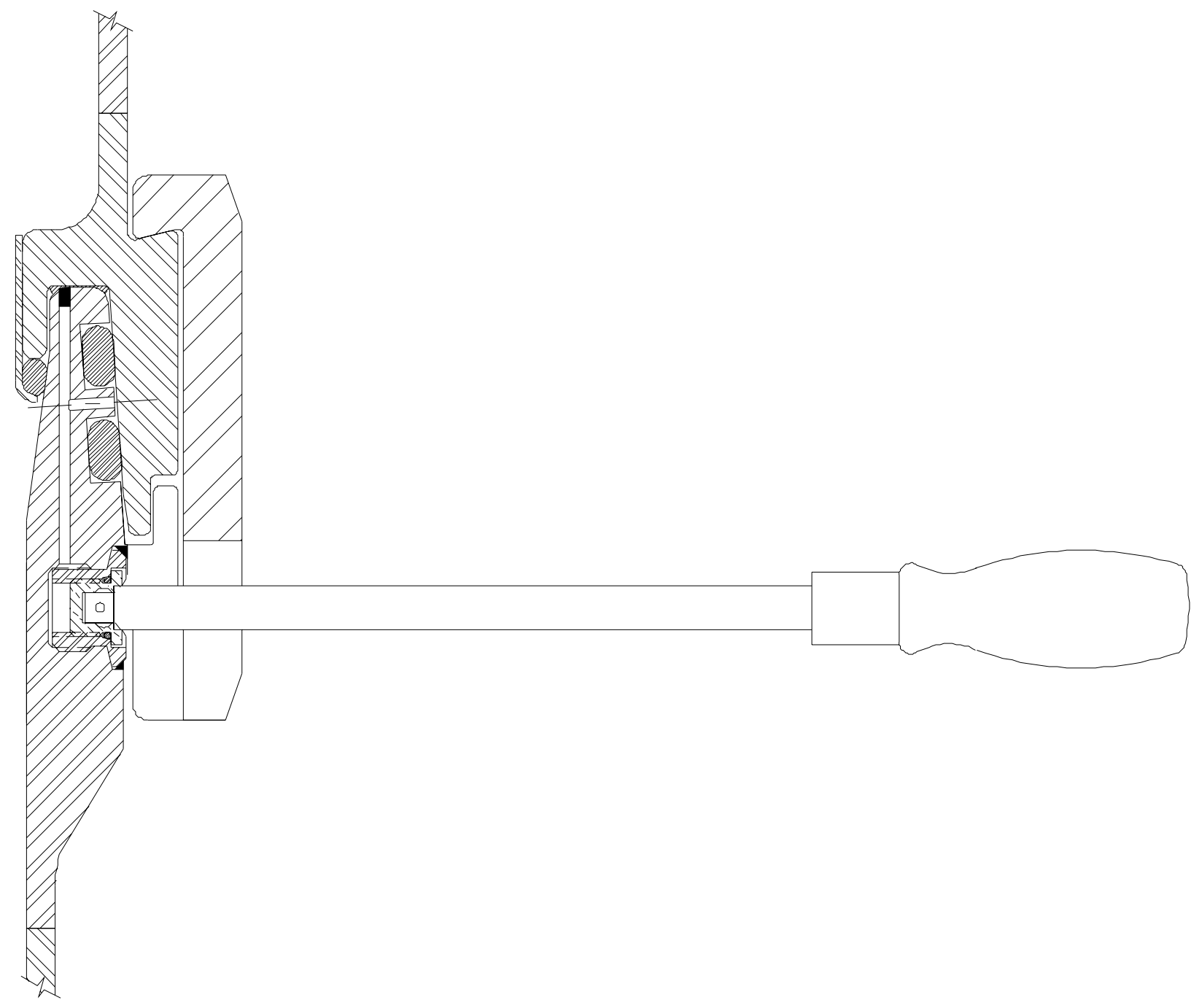

Note: Proto brand tools should be used to ensure proper fit. 
Figure 1.11 - ICV Seal Leak Check Tool (2077-093-A1)
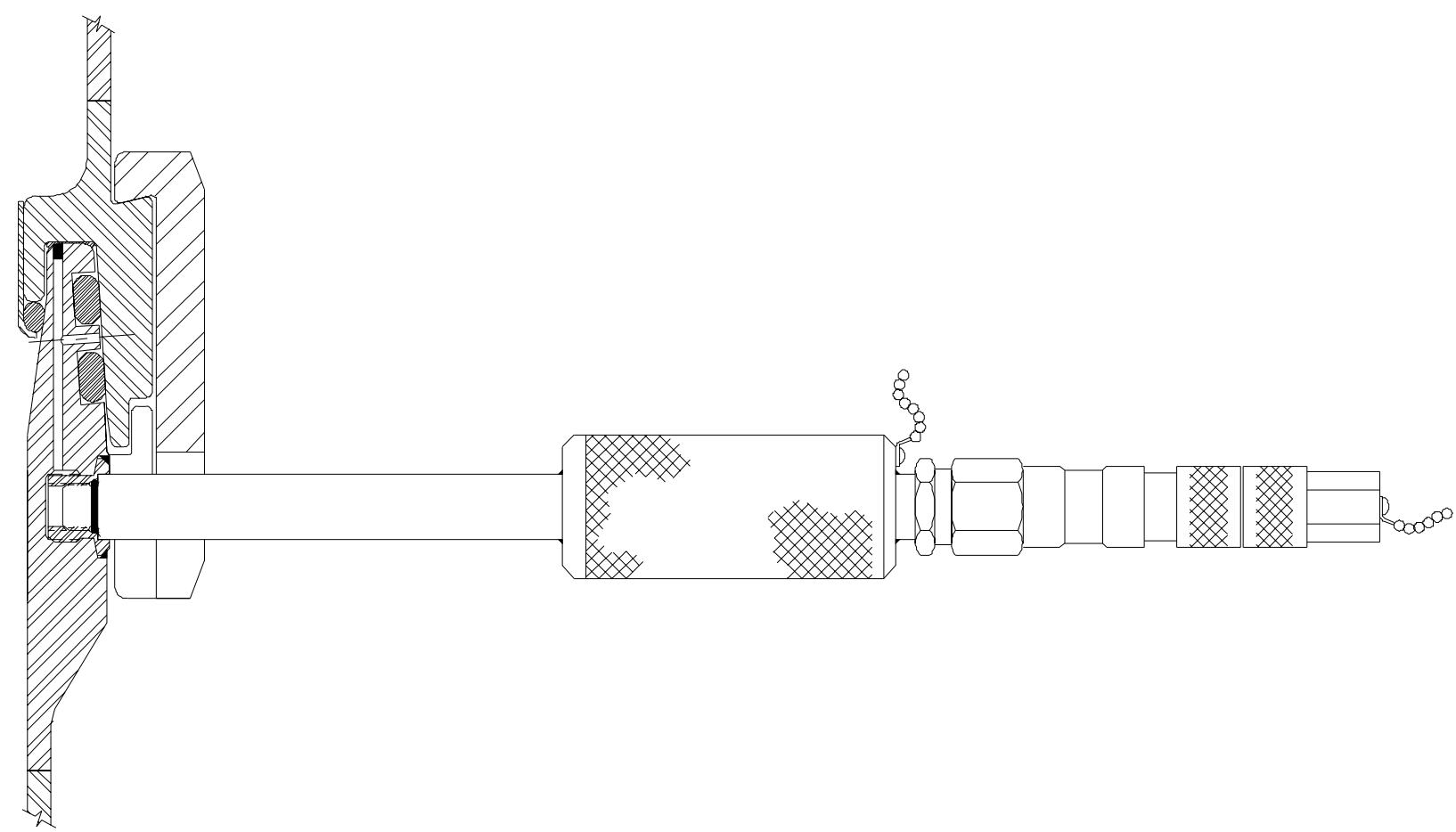

Not to scale

Note: Uses Parker O-ring, Buna-N, Part \# 3-905 


\section{Figure 1.12 - ICV Components}

1/4" SQUARE DRIVE (TORQUE 55-65 LB-IN)
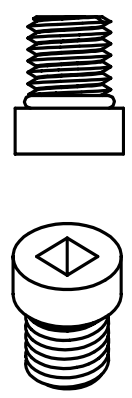

ICV SEAL TEST PORT PLUG \& $0-R I N G$ (AS-568-905)
1/4" SQUARE DRIVE (TORQUE 55-65 LB-IN)

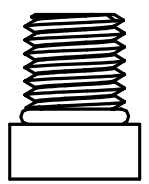

3/8" SQUARE DRIVE (TORQUE 55-65 LB-IN)
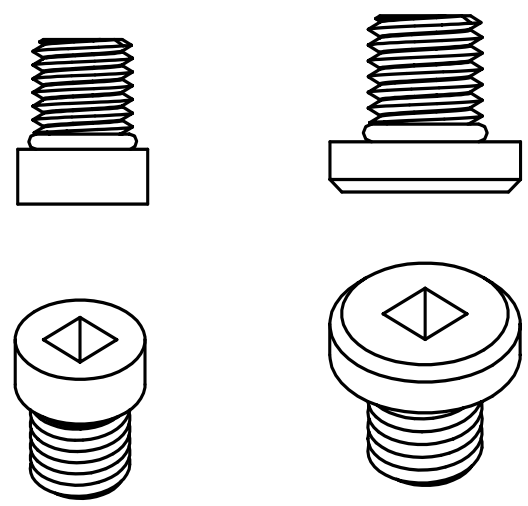

ICV INNER VENT PORT PLUG \& $0-$ RING (AS-568-906)

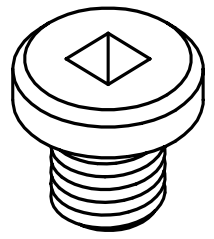

ICV OUTER VENT PORT PLUG \& O-RING (AS-568-910)
3/8" SQUARE DRIVE (TORQUE 55-65 LB-IN)
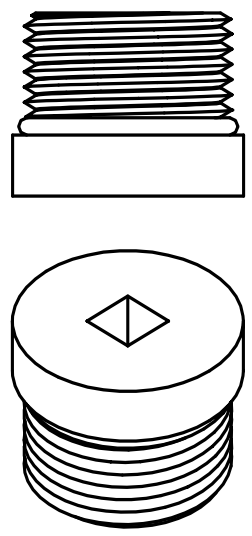

ICV VENT PORT COVER \& SEAL

(1/16" THK. GASKET OR AS-568-916 O-RING)

/8" ALLEN DRIVE

(TORQUE 28-32 LB-FT)
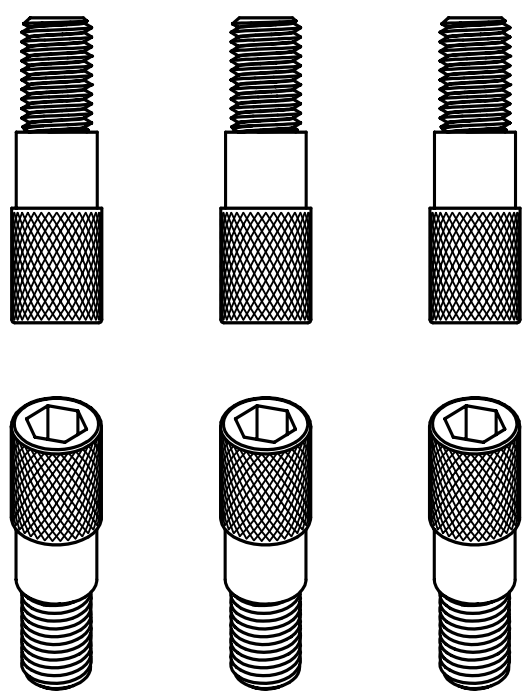

ICV LOCK RING BOLTS (3)

NOT TO SCALE 
Figure 1.13 - OCA / OCV Components
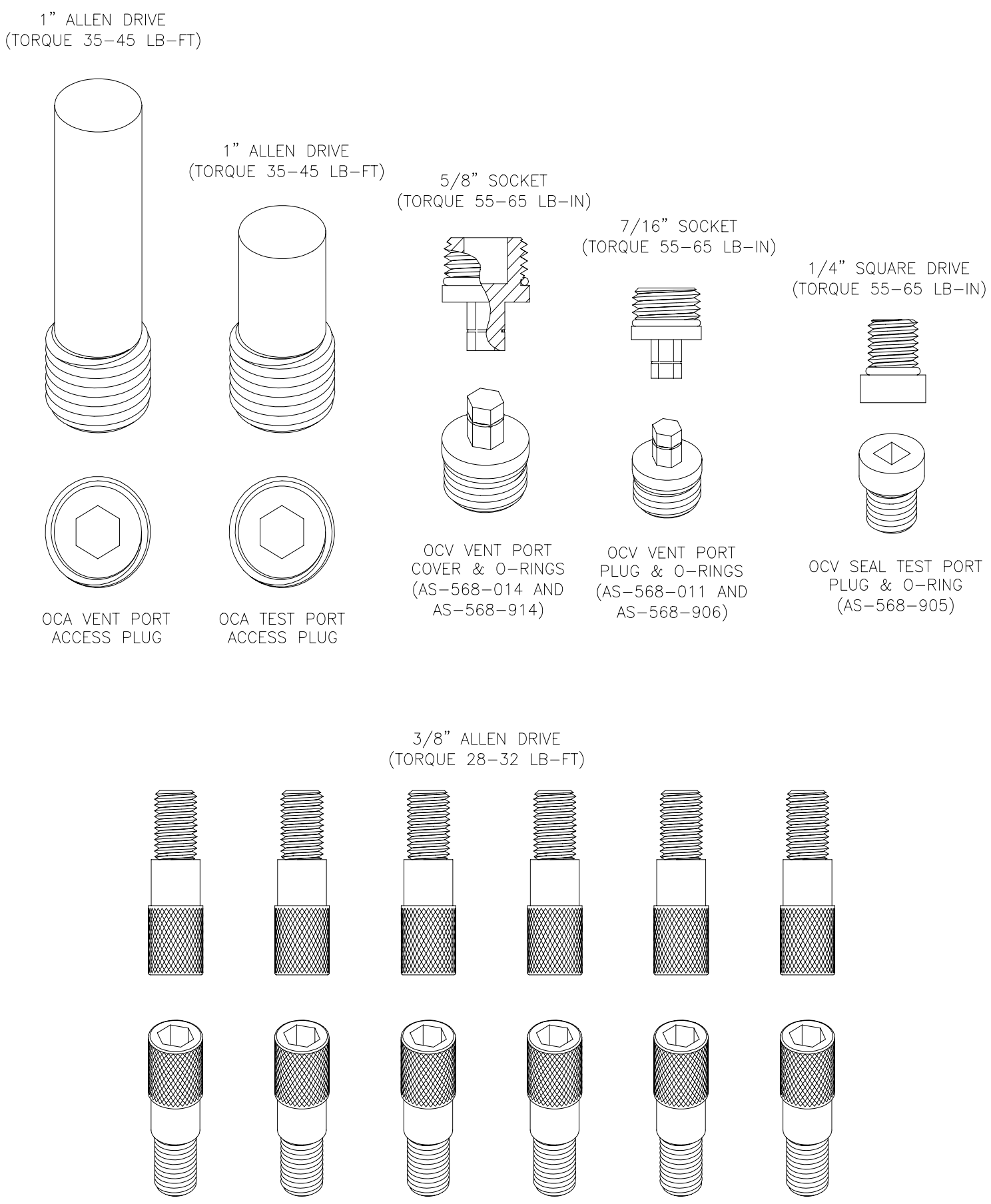

OCV ACTUATOR RING BOLTS (6)

NOT TO SCALE 


\subsubsection{Spare Parts/Bench Stock}

Table 1.3 lists the spare parts that support replacement of packaging components during routine operations. Levels of supply are based on historical data relating to the frequency of usage of packaging and are expressed in terms of the quantity of parts that should be on hand with minimum/maximum levels to be stocked. A bench stock inventory shall be conducted quarterly to determine shortages. Replacements will be provided by the WIPP M\&O contractor $\mathrm{CH}$ Packaging Maintenance Engineer. All items shall be checked against their listed shelf life. The on-hand and needed columns may be used to conduct inventories. Inventory data shall be sent to the WIPP M\&O contractor CH Packaging Maintenance Engineer quarterly (at the end of March, June, September, and December) for parts replacement.

Figures 1.12 and 1.13 show ICV and OCV parts. As parts are removed from the packaging, they should be placed in the shadow board. A laminated copy of these figures placed behind the shadow board will assist in parts accountability and identification. 


\begin{tabular}{|c|c|c|c|c|c|}
\hline Description & Part No. & $\begin{array}{l}\text { P.O. } \\
\text { No. }\end{array}$ & $\begin{array}{l}\operatorname{Min} / \\
\operatorname{Max}\end{array}$ & $\begin{array}{c}\text { On } \\
\text { Hand }\end{array}$ & Needed \\
\hline ICV/OCV seal test port plug & $156-07$ & & $1-3$ & & \\
\hline ICV outer vent port plug & $156-09$ & & $1-3$ & & \\
\hline ICV inner vent port plug & $156-10$ & & $1-3$ & & \\
\hline ICV vent port cover & $156-11$ & & $1-3$ & & \\
\hline OCA seal test port access plug & $156-12$ & & $1-3$ & & \\
\hline OCA vent port access plug & $156-13$ & & $1-3$ & & \\
\hline OCA test port thermal plug (foam) & $156-14$ & & $1-3$ & & \\
\hline $\begin{array}{l}\text { OCA test port thermal plug (ceramic } \\
\text { paper) }\end{array}$ & $156-14 \mathrm{~A}$ & & $1-3$ & & \\
\hline OCA vent port thermal plug (foam) & $156-15$ & & $1-3$ & & \\
\hline $\begin{array}{l}\text { OCA vent port thermal plug (ceramic } \\
\text { paper) }\end{array}$ & $156-15 A$ & & $1-3$ & & \\
\hline OCV vent port plug & $156-17$ & & $1-3$ & & \\
\hline OCV vent port cover & $156-18$ & & $1-3$ & & \\
\hline Annulus debris seal & $156-21$ & & $1-2$ & & \\
\hline ICV locking ring bolt & 156-A1 & & $1-6$ & & \\
\hline OCV locking ring bolt (HalfPACT) & $156-\mathrm{A} 1$ & & $1-6$ & & \\
\hline OCV locking ring bolt (TRUPACT-II) & $\begin{array}{l}156-\mathrm{A} 1 \\
\text { or } \\
156-\mathrm{A} 2\end{array}$ & & $1-6$ & & \\
\hline OCV locking Z-flange screw & $160-13$ & & $2-10$ & & \\
\hline OCA lid guide plate screw & $160-14$ & & $2-10$ & & \\
\hline OCV upper main O-ring & $160-15$ & & $3-15$ & & \\
\hline OCV vent port cover O-ring & $160-16$ & & $5-10$ & & \\
\hline OCV vent port plug O-ring & $160-17$ & & $5-10$ & & \\
\hline OCV vent port plug handling O-ring & $160-18$ & & $5-15$ & & \\
\hline OCV vent port cover handling O-ring & $160-19$ & & $5-15$ & & \\
\hline OCV lower main O-ring & $160-24$ & & 3-15 & & \\
\hline OCV seal test port plug O-ring & $160-26$ & & $5-10$ & & \\
\hline $\begin{array}{l}\text { ICV/OCV locking ring bolt threaded } \\
\text { insert }\end{array}$ & $160-28$ & & $1-6$ & & \\
\hline $\begin{array}{l}\text { OCA forklift pocket cover threaded } \\
\text { insert (for sites that remove packaging } \\
\text { from trailer) }\end{array}$ & $160-29$ & & $1-2$ & & \\
\hline
\end{tabular}




\begin{tabular}{||l|c|c|c|c|c||}
\hline \multicolumn{1}{|l|}{ Table 1.3 - Spare Parts (Bench Stock) } & Part No. & $\begin{array}{c}\text { P.O. } \\
\text { No. }\end{array}$ & $\begin{array}{c}\text { Min/ } \\
\text { Max }\end{array}$ & $\begin{array}{c}\text { On } \\
\text { Hand }\end{array}$ & Needed \\
\hline \hline & $160-30$ & & $2-10$ & & \\
\hline \hline OCA forklift pocket screw & $160-31$ & & $2-10$ & & \\
\hline OCA forklift pocket washer & $163-02$ & & $1-3$ & & \\
\hline OCA lid lift pocket tube & $163-03$ & & $1-6$ & & \\
\hline $\begin{array}{l}\text { OCA lid lift pocket tube attachment } \\
\text { screw }\end{array}$ & $163-04$ & & $1-6$ & & \\
\hline Lift pocket washer & $163-05$ & & $1-6$ & & \\
\hline OCA lift pocket cover fastener & $163-06$ & & $1-6$ & & \\
\hline OCA lift pocket cover plate & $163-07$ & & $1-5$ & & \\
\hline OCA lift pocket cover lanyard & $163-08$ & & $2-10$ & & \\
\hline OCA lift pocket cover plate screw & $163-09$ & & $2-10$ & & \\
\hline OCA lift pocket cover nut & $163-10$ & & $1-6$ & & \\
\hline OCA lift pocket cover clip & $170-06$ & & $1-3$ & & \\
\hline Burn out plug & $171-11$ & & $1-2$ & & \\
\hline Forklift pocket cover, right side & $171-12$ & & $1-2$ & & \\
\hline Forklift pocket cover, left side & $180-06$ & & $1-6$ & & \\
\hline ICV upper and lower spacer washer & $180-09$ & & $3-15$ & & \\
\hline ICV upper main O-ring & $180-10$ & & $2-10$ & & \\
\hline ICV lower spacer screw & $180-11$ & & $5-10$ & & \\
\hline ICV wiper O-ring holder driver screw & $180-16$ & & $3-15$ & & \\
\hline ICV vent port cover seal (gasket) & $180-16 A$ & & $3-15$ & & \\
\hline ICV vent port cover seal (O-ring) & $180-19$ & & $3-15$ & & \\
\hline ICV lower main O-ring & $180-20$ & & $3-15$ & & \\
\hline ICV upper spacer screw & $180-21$ & & $3-15$ & & \\
\hline ICV outer vent port plug seal & $180-22$ & & $5-10$ & & \\
\hline ICV inner vent port plug seal & $180-23$ & & $1-6$ & & \\
\hline $\begin{array}{l}\text { ICV fastener, ICV upper and lower } \\
\text { spacer }\end{array}$ & $180-24$ & & $5-10$ & & \\
\hline ICV seal test port plug O-ring & $180-25$ & & $1-2$ & & \\
\hline ICV lid debris seal & $180-26$ & & $1-2$ & & \\
\hline ICV lid debris seal tape & & $1-2$ & & \\
\hline ICV wiper O-ring seal & & & \\
\hline \hline
\end{tabular}




\subsubsection{Transport Trailer}

The transport trailer is designed to transport loaded packages. Air-ride suspension trailers are designed with a goose neck that is equipped with a standard king-pin arrangement.

Each trailer is equipped with tie-down devices used for securing packages to the trailer (four tie-downs for each package). The tie-downs include adjustable length U-bolts that interface with and clamp down on corresponding lugs on the packaging.

\subsection{GENERAL REQUIREMENTS}

\subsection{Records Maintenance}

Packaging users must comply with 10 CFR 71.91 regarding records. Specifically, records regarding inspections, tests, and maintenance must be retained for a period of three years after the life of the package to which they apply. Records relating to each shipment must be maintained for a period of three years after the shipment.

All records of maintenance activities performed on the packaging will be maintained by the WIPP M\&O contractor. Records are designated as QA records and will be maintained as permanent records.

\subsection{Document Distribution}

Upon completion, original maintenance records and copies of supporting documentation shall be transmitted to the WIPP M\&O contractor $\mathrm{CH}$ Packaging Maintenance Engineer, P.O. Box 2078, Carlsbad, NM 88221, and become a part of the permanent $\mathrm{CH}$ packaging system record.

Users preparing the maintenance records should retain a copy for their files.

The work instructions should be used as a checklist. Data attachments to the work instructions must be transmitted to WIPP with the original $\mathrm{CH}$ Packaging maintenance record, unless stated otherwise in the work instruction.

\subsection{Approved Work/Periodic Maintenance Instructions}

Periodic and unscheduled maintenance tasks shall be accomplished using preapproved work instructions and/or one-time use repair procedures.

Approved work and periodic maintenance instructions are listed in Attachment B. These are available on the internet at: http://www.wipp.ws/library/t2omi/t2omi.htm. Completed originals will be filed with and become part of the permanent record. For approved work instructions intended for one-time use (either the WIPP M\&O contractor or vendor-generated), the original will become part of the permanent record.

\subsection{Material Control}

All initial and replacement components are procured by WIPP and shall be verified as complying with applicable material requirements as specified in SARP drawings. Inspection reports, certified material test reports, and material certificates of conformance shall be maintained by the WIPP M\&O contractor.

Spare parts will be furnished by the WIPP M\&O contractor. The parts package will be labeled with part number, description, WIPP purchase order number, and shelf-life 
expiration date, if applicable. Users will segregate and store parts by part number. Parts having the same part number but different purchase order numbers shall be segregated to maintain their individual traceability to the source purchase order. Site bench stock will be maintained at levels consistent with that shown in Table 1.3. Shelf life should be examined prior to issue of O-rings, with priority of issue given to O-rings with the shortest remaining shelf life. Shelf life should also be considered when conducting inventories and requesting additional stock.

All replaced (used) components should be disposed of in accordance with site procedures. If return of used components is deemed necessary for analysis, usage trends, or investigation, a formal request for return will be issued to user sites.

\subsection{Quality Assurance Requirements}

A QA system, meeting controlling functions of the applicable 18 criteria of 10 CFR 71, Subpart $\mathrm{H}$, shall be in place at the loading and unloading facilities as defined by DOE Order 460.2, "Departmental Materials Transportation and Packaging Management." Annex 2 of the NRC Regulatory Guide 7.10 shall be used as a guideline. These requirements also apply to maintenance, repair, replacement, and/or modifications, as approved by the owner.

Existing QA programs may be used to satisfy the above requirements provided a review has been made as to its applicability to the scope of activities performed by each participant. It is the responsibility of the involved participant to obtain approval of their QA program from the appropriate DOE Field Office.

\subsection{Training Requirements}

Users shall have the responsibility for a training program specific to this work scope to ensure that qualified personnel, experienced in their assigned tasks, satisfactorily perform maintenance, nondestructive testing, leak testing, component replacement, and related operations. To ensure uniformity of training, Attachment $\mathrm{C}$, Training Requirements, is included and provides the minimum requirements that must be included in site qualification cards for those sites which use the packaging. Users may supplement these requirements as appropriate.

Leak test personnel shall meet the requirements of the American Society of Nondestructive Testing (ASNT) Recommended Practice No. SNT-TC-1A, June 1980 edition and supplement.

\subsection{Maximum Packaging Weights}

The maximum gross shipping weight of a TRUPACT-II shipping package is 19,250 lb.

The maximum gross shipping weight of a HalfPACT shipping package is $18,100 \mathrm{lb}$.

The maximum allowable gross shipping weight for three loaded packages, including the tractor and trailer, is $80,000 \mathrm{lb}$. The WIPP Waste Information System (WWIS) Packaging Reference Data Table may be used to obtain packaging weights.

\subsection{Forklift Specifications}

Forks shall have a minimum bearing area of 960 square inches (two forks, 8 inches wide by 60 inches long). The forks shall be at the minimum spread to ensure that the package is centered with respect to the direction of the forklift. Forklift capacity must equal or exceed 10 tons at 48 inches. 
Bumper pads should be provided on the face of the forklift if tip-back is used. A suitable bumper pad would be a 62-inch long, 24-inch high stainless steel plate with a 48-inch radius. A thin pad of neoprene, rubber, or similar material would further preclude damage. The bumper should be located at the upper surface of the fork tine at the appropriate angle to the face of the forklift.

\section{$2.9 \quad$ Shipping Requirements}

When shipping an empty packaging to WIPP, a copy of the radiation and contamination survey and survey map (internal [if opened] and external) performed when the packaging was last closed, will be faxed to the WIPP M\&O contractor Radiological Control at (505) 234-8963, or 234-6030 (Shipping Coordination), prior to departure.

\subsection{Shipment Scheduling}

Package shipments are coordinated by the WIPP M\&O contractor. Once agreed upon by the shipping site traffic manager and the representative, the WIPP M\&O contractor will enter the advance shipment schedule into the DOE TRANSCOM satellite-based shipment tracking system. Based on this schedule, the shipper is responsible for entering the bill of lading into TRANSCOM at the time of shipment. Prior to departure of the shipment, the shipper is required to change the Designated User in the TRANSCOM bill of lading to that of the WIPP Central Monitoring Room. In addition, only shipments approved in the WWIS shall be accepted for transport to WIPP.

\subsection{Nonconformance Reports}

Conditions encountered during operation or inspection of the packaging that are not correctable by using the work instructions in Attachment B should be brought to the attention of the WIPP M\&O contractor $\mathrm{CH}$ Packaging Engineer for resolution. Discrepant conditions not corrected by the packaging user shall be entered into the Computerized History and Maintenance Planning System (CHAMPS) in the Deferred Maintenance module. Upon receipt of the packaging at WIPP, an evaluation of the noted condition will be performed to determine whether a Condition Adverse to Quality (CAQ) exists. If a CAQ exists, the packaging will be tagged out-of-service until corrected and a nonconformance report may be issued. Deferred maintenance tasks will be performed during periodic maintenance or on an as needed basis.

\subsection{PAYLOAD PREPARATION}

The $\mathrm{CH}$ Packaging Operations Manual for the payload assembly is available on the internet at http://www.wipp.ws/library/t2omi/t2omi.htm. Users are responsible for ensuring they are using the current revision and change notice.

\subsection{PACKAGE OPERATING INSTRUCTIONS}

The $\mathrm{CH}$ Packaging Operations Manual is available on the internet at:

http://www.wipp.ws/library/t2omi/t2omi.htm. Users are responsible for ensuring they are using the current revision and change notice.

The remainder of this section provides users the benefit of lessons learned when using $\mathrm{CH}$ packaging. The user should note that many of the techniques are intentionally NOT 
included in DOE/WIPP 02-3184, CH Packaging Operations Manual, unless they affect safety.

\subsection{General Information on Section 4.0}

Should users decide to prepare their own site-specific procedures, they need only address the functions performed at their site. If fixed loading facilities are used, the user need not include removal of the packagings from the trailer. If only empty packagings are received, there is no need for a procedure on receipt of packages.

DOE/WIPP 02-3184 may always be used as an authorized operating procedure.

Section 4.3 includes applicable notes and cautions associated with packaging operations with which a user should be familiar.

\subsection{Operating Tips and Techniques}

The following information is provided as guidance for training in $\mathrm{CH}$ packaging operations. It provides supporting information to DOE/WIPP 02-3184, CH Packaging Operations Manual.

\subsubsection{Unloading a Package from a Trailer}

The adjusting nut(s) must be loosened until the tension has been released from the tiedown assembly. The assembly can then be lifted and rotated outward away from the tie-down lugs. The assembly must be lowered as far as possible onto the trailer bracket below the tie-down lugs to prevent damage to the packaging exterior and the tie-down assembly.

Experience has shown that rotating the forklift pocket covers and tightening the screws is more than adequate to hold the covers out of the way while transporting the packaging from the trailer to the loading/unloading area.

When using a forklift in conjunction with the packaging, the fork tines must fully engage the pockets. This, however, does not imply contact between the fork uprights and the packaging exterior. In addition, it is necessary to keep the package level to prevent damage to the exterior surface (i.e., do NOT tilt the forks back for transport).

\subsubsection{OCA / ICV Lid Removal}

Before unlocking the OCA lid, the alignment of the seal test port, in relation to the lid, must be checked to verify that the seal test tool can be installed with no binding. In the event the alignment is not correct, the lid should be temporarily marked to show the proper orientation of the locking ring when aligned correctly. This marking can then be used to realign the locking ring after the lid has been removed and is on the lid stand.

The ACGLF legs must be verified to be locked into the load/lift fixture prior to placing any load weight on the ACGLF. The legs are locked when the green LOCKED lights are $\mathbf{O N}$ and the amber UNLOCKED lights are OFF at the ACGLF console. Verify the legs physically rotate when the leg Lock/Unlock switch is engaged in either position.

The ACGLF counterweights should be used to assist in the removal of OCA and ICV lids. Rotating the weights clockwise, and/or counterclockwise, while placing tension on the crane will allow the operator to remove a lid.

When the ACGLF is used properly, the lid will shift toward the high point, compensating for an uneven lift. This is done when the weights are rotated toward the area of the lid 
that is at the highest point. After the weight shift has occurred, the lid can be lifted normally by repositioning the weights to the $180^{\circ}$ and $000^{\circ}$ positions and continuing with the upward motion of the crane.

In the event the ICV has rotated within the OCV during shipment, the following corrective actions can be implemented. The operator can lift an empty ICV with the ACGLF and crane, and reorient it to the required position, or insert the T-handles into the slots and rotate the ICV as necessary. When the ICV is loaded, the T-handles must be inserted into the slots and the ICV rotated as necessary.

When OCA and ICV lid component parts are removed from their installed positions, they should be placed in a tray that includes a full-scale picture or drawing of all parts. There should be space to set each part in front of its associated picture to allow for easy identification of what parts have and have not been removed during the lid removal process. This tray should also provide for the segregation of OCA parts from ICV parts.

The operator should verify that the proper T-handles are being used for the respective lids. The ICV T-handles have a longer shaft on the pins than the OCA T-handles due to the difference in thickness between the locking rings. If the ICV T-handles are used in the OCA locking ring there will be excessive play, which creates the potential for damaging the locking ring.

In addition to the T-handles, there are locking ring tools which are extensions to aid the operator in the rotation of the locking rings. They provide additional leverage and control to prevent slamming the locking ring up against the stop tabs. These tools should be used for all locking ring manipulations to minimize the possibility of damage to the locking ring stop tabs.

After evacuating the OCV or ICV, the associated vent port tool must be removed. This must occur prior to lifting the lid to prevent damage to the tool, the locking ring, the lid and/or the body of the packaging during lid removal. It also facilitates thread inspections, and allows the cavity to return to atmospheric pressure in less time because the vent port has a larger opening than the vent port tool adaptor.

It may be necessary to hold the vent port tool to prevent the rotation of the ICV body when rotating the ICV locking ring. If this is done, the operator must hold the tool at the base (i.e., closest to the body). If the tool is held at the end by the rotating handle, the lateral stresses being applied could break the tool.

When lifting the OCA lid, verify through the use of a load cell that the load exerted on the lift pockets does not exceed $7,500 \mathrm{lb}$. (Load cell indication of 10,000 lb minus the weight of the ACGLF @ 2,500 lb=7,500 lb load.) An indication of 10,000 lb or greater may mean the lid is binding.

When lifting the ICV lid, verify through the use of a load cell that the load exerted on the lift pockets does not exceed $5,000 \mathrm{lb}$. (Load cell indication of 7,500 lb minus the weight of the ACGLF@ 2,500 lb=5,000 lb load.) An indication of 7,500 lb or greater may mean the lid is binding.

\subsubsection{Inspections and Cleaning}

The alignment of the seal test port with the OCA lid must be verified prior to reinstalling the lid. If necessary, the locking ring can be realigned, with the lid on the stand, using the marks made on the lid prior to unlocking and removal. Using the OCA T-handles, three operators located around the circumference of the lid can lift slightly and evenly on the locking ring and rotate it in the required direction to realign the seal test port. 
When applying the vacuum grease to the threads of the plugs and covers, and their associated O-rings, the term "very light coat" should be understood to mean no more than what is necessary to give the O-rings a glossy appearance or the threads a dull appearance.

The main O-rings should be lubricated with approximately one tablespoon of vacuum grease. When two operators (recommended) are greasing a main O-ring, they should use approximately one-half tablespoon each, or one operator should use approximately one tablespoon while the other assists in holding the main O-ring during greasing.

When applying the nickel-bearing lubricant to the threads of the access covers, bolts, and/or access ports, use only enough to give the threads a dull appearance.

Due to the leak test sensitivity, it is imperative that all sealing surfaces be cleaned thoroughly. If not, a failed leak test may result, and it will be necessary to repeat the cleaning process.

If water is found in the ICV cavity, it is necessary to remove the water by means of a wet/dry vacuum, or by entering the cavity and using absorbent materials to soak up the water. After this is accomplished, it is then necessary to remove the ICV to inspect the OCV for water, and remove the water if found. When removing the ICV, care should be taken to prevent damage to the bottom, and to verify that the ICV is placed in a safe, secure place.

\subsubsection{Loading a Payload}

When initially raising a payload with the ACGLF to balance it, the operator should note the counterweight positions. These positions are to be written on tape affixed to the top of the payload in the vicinity of the leg opposite the two electrical junction boxes on the ACGLF.

The payload must be balanced to minimize the possibility of damage to the interior of the ICV. Care should be exercised to avoid hitting, scraping, or binding the payload assembly against the ICV body flange, because damage could result.

The payload must be aligned such that the center-of-gravity is in alignment with the centerline of the trailer. This is necessary to minimize the effects of an unbalanced load on the safe handling of the truck-trailer assembly when traveling over the road.

\subsubsection{Unloading a Payload}

Prior to removing the payload, the operator must note the counterweight positions marked on the top of the payload. This will indicate the proper orientation of the ACGLF legs and let the operator know where to position the weights for a balanced lift.

The payload must be balanced prior to being removed from the ICV to prevent damage to the interior of the ICV body.

\subsubsection{ICV / OCA Lid Installation}

The ICV is designed for safe operation with a full internal vacuum. However, due to the possible presence of VOCs in the payload, general operations of the ICV shall be accomplished using less than 15-inch-Hg vacuum.

An appropriate T-handle should be installed in the slots of the locking ring near the vent port to assist in aligning the lid during installation. 
The operators should check for proper alignment of the unlock arrows with the seal test port arrows, and check for proper orientation of the vent port with the cutout in the locking ring during alignment of the lids. The operators must also verify that the lid is balanced when lowered. They can listen for air rushing out of the vent port to indicate that the lid has fully seated.

Care should be taken to avoid scraping the guide plates against the ICV locking ring, by ensuring that the OCA lid is centered directly over the OCA body during installation.

When installing a lid on a packaging, it is quicker to vent the internal pressure by removing the vent port tool than to leave the tool in place and insert an adaptor. The vent port has a larger opening than the vent port tool adaptor.

\subsubsection{Loading Packaging onto a Trailer}

When loading packaging onto a trailer, the forklift operator is required to use a spotter at all times.

It is necessary to align the tie-down lugs with the tie-down assemblies prior to setting the packaging into place. The operator should lower the packaging slowly onto the trailer in the designated location.

The packaging designated for the \#1 trailer position should be loaded first, the packaging designated for position \#2 (if applicable) next, and the packaging designated for position \#3 (if applicable) last. This ensures the maximum amount of operating room for the forklift operator.

When packaging designated for the trailer has been loaded, each of the tie-down assemblies must be lifted up and positioned toward and over the packaging tie-down lugs. The operator should then engage the assembly into the packaging tie-down lug recesses. The spring safety pins, padlocks, or other mechanisms should be installed to prevent movement during shipping.

When tightening the adjustment nut(s) for each of the tie-down assemblies, the operator is required to obtain a gap condition of 0.070 to 0.100 inches using a Go/No Go gauge. If this gap condition cannot be obtained on a tie-down assembly, it will be necessary to remove, disassemble, and clean the tie-down assembly. Once this has been completed, the tie-down assembly, must be reassembled and tightened, and the gap verified to be within the tolerance stated above.

The forklift pocket covers may be installed at any time after the packaging is loaded onto the trailer.

\subsubsection{Lifting a Stuck Lid}

The crane should be operated at the slowest possible operating speed when attempting to lift a stuck lid.

When using heat guns, it is necessary to ensure that the locking ring is heated evenly. This may require the use of more than one heat gun. The time limits are provided as a guideline to ensure the even and complete heating of the locking ring. Additional heating time may be required in colder climates. This should be determined by the $\mathrm{CH}$ Packaging Maintenance Engineer. 
If it is necessary to pressurize a packaging to remove a stuck lid, the Abnormal Operations Section (Section 3.0), of DOE/WIPP 02-31284 must be followed as written to prevent personnel injury/contamination and/or equipment damage.

Under no circumstances are the safe working limits of the crane, ACGLF, and/or any associated rigging materials to be exceeded to remove a stuck lid. To do so could result in undue stresses and damage to equipment, personnel injury, and various other costly and unnecessary occurrences.

\subsection{Notes and Cautions Regarding Operating Instructions}

\subsubsection{Notes:}

The package unloading operation shall only be performed in a dry environment. In the event of precipitation during outdoor unloading or loading operations, precautions such as covering the OCA and ICV cavities shall be implemented to prevent precipitation from entering the package interior cavities. If precipitation does enter the interior cavities, all freestanding water shall be removed prior to loading the package for shipment, and handled according to the site waste management procedures.

The ACGLF may be left in place while leak tests are performed so as to be available if the leak tests fail and a lid must be removed for additional cleaning.

The ICV is designed for safe operation with a full internal vacuum. However, due to the possible presence of VOCs in the payload, general operations of the loaded ICV shall be accomplished using less than 15-inch-Hg vacuum.

Verify the lugs are aligned with the tie-down U-bolts prior to placing the package on the trailer.

If required, clean and/or dry the package before transport to a designated area. The package may be cleaned with water and damp cloths or a soft brush. Used cleaning materials should be managed according to site waste management procedures.

When replacing main O-ring(s), leak testing is not required if shipping an empty container (see WI-CH.02). However, a Leak Check Required tag identifying the containment O-ring(s)/seal(s) replaced must be attached to the vent port indicating testing is required prior to loaded shipment and the appropriate maintenance record entries are required.

For shipments to WIPP, the shipper should verify that each payload container number has been entered into the WWIS and verify that the shipment has been approved by the WIPP WWIS Data Administrator. 


\section{NOTE}

When loading packages on a trailer, or loading payload into packaging that is already on a trailer, the following applies:

-Packages having a gross weight difference (heaviest to lightest) of 2,000 lb or less can be considered equal and do not require a specific sequence for positioning on the trailer.

-Packages having a gross weight difference (heaviest to lightest), greater than 2,000 pounds shall be positioned on the trailer as follows:

\begin{tabular}{|l|l|l|l|l|}
\hline \multirow{4}{*}{$\begin{array}{l}\text { TRAILER } \\
\text { FRONT }\end{array}$} & *1. Heaviest & Medium & Lighter & \\
\cline { 2 - 4 } & 2. Heaviest & Lighter & Medium & \\
\cline { 2 - 4 } & *3. Heaviest & Lighter & None & REAILER \\
\cline { 2 - 4 } & 4. Lighter & Heaviest & None \\
\cline { 2 - 4 } & 5. Heaviest & None & None & \\
\hline \multicolumn{2}{|l|}{ The asterisk indicates the preferred, but not mandatory method. } \\
\hline
\end{tabular}

Rotation of the ACGLF weights should be used to assist in the removal of the OCA and ICV lids; however, care must be taken to verify the weights are positioned in the $180^{\circ}$ and $000^{\circ}$ positions prior to lifting either lid.

Security seals are only required on loaded shipments. A Leak Test Required tag attached to the vent port seal boss indicates that containment rings/seals were replaced prior to an empty shipment per WI-CH.01 and WI-CH.02, and a leak test is required prior to shipping a package. After the leak test, remove the tag and forward a copy of the leak test results to the $\mathrm{CH}$ Packaging Maintenance Engineer to be filed with the original work instructions and maintenance record.

Refer to a site-specific lift fixture Operation and Maintenance Manual for detailed ACGLF operating instructions.

The radiation/contamination surveys listed in the body of the operations procedures are recommendations. Site-specific procedures and policies shall be referenced to determine the necessity and sequencing of actual surveys and hold-points.

\subsubsection{Cautions:}

A physical check shall be made to verify the air bags on the trailer have fully inflated before the loaded trailer is moved by a user site trailer jockey. Failure to do so may cause the tires to rub on the bottom of the rear packaging.

Tip-back may damage the exterior surface when a forklift is used to reposition a packaging.

Three operators should be able to rotate the locking ring with reasonable effort. Do not attempt to rotate the OCA or ICV locking ring assembly with mechanical force other 
than the locking ring tool (an extension to provide additional leverage and control). Care should be used to prevent the locking rings from slamming into the stops.

Verify that the two ACGLF counterweights are located at the $180^{\circ}$ and $000^{\circ}$ positions, respectively, prior to lifting an ACGLF, lid, or payload.

Exceeding a crane load cell indication of $10,000 \mathrm{lb}$ can damage OCA lid lift points.

Exceeding a crane load cell indication of $7,500 \mathrm{lb}$ can damage ICV lid lift points.

The operator shall obtain protective clothing and equipment prior to entering the OCV cavity. The operator shall also enter the OCV cavity using precautions to preclude damage to the OCV body sealing flange.

Operators shall avoid damage caused by hitting or scraping the payload assembly against the ICV body flange.

\subsection{PACKAGE MAINTENANCE INSTRUCTIONS}

This section describes the maintenance program used to ensure continued performance of the packaging (see definition section for annual and five-year maintenance). The annual maintenance tests and inspections described in this section shall be performed within 12 months prior to each shipment. Annual maintenance tests and inspections need not be performed for out-of-service packages. The five-year cycle for structural pressure tests shall begin when the packaging is first placed into service and shall include cumulative in-service time only.

All maintenance, repairs performed, or components replaced will be documented using the maintenance record. Information regarding preparation of the maintenance record is outlined in Section 5.6. The maintenance record is available at:

http://www.wipp.ws/library/t2omi/t2omi.htm. Records shall be maintained by the WIPP $\mathrm{M} \& \mathrm{O}$ contractor to document completion of the maintenance schedule.

If a deficiency is found which is not covered by this document, or which is beyond the repair capability of the discovering site, that site will follow its approved procedure for reporting deficiencies and contact the $\mathrm{CH}$ Packaging Maintenance Engineer within 24 hours for disposition. All questions regarding the continued integrity of packagings shall be addressed to the WIPP M\&O contractor Transportation Program, P.O. Box 2078, Carlsbad, NM 88221.

Pre-approved work instructions are listed and linked in Attachment B. Maintenance activities not within the scope of pre-approved work instructions shall be performed in accordance with procedures that have been reviewed and approved by the WIPP M\&O Contractor prior to implementation. Recommendations for new work instructions or modifications to existing work instructions shall be forwarded to the WIPP M\&O contractor Transportation Program.

Scheduled and unscheduled maintenance will be coordinated by the WIPP M\&O contractor Transportation Program. Maintenance will be scheduled so as to maximize the availability of packaging.

NOTE: Sections 5.1 through 5.4 are normally done at WIPP or by a WIPP M\&O contractor subcontracted vendor. Work Instruction WI-CH.15, Annual and Five-Year Maintenance Inspections, should be used as a checklist when performing these inspections. 
Structural, periodic, and maintenance leakage rate test procedures are found in DOE/WIPP 02-3185, CH Packaging Maintenance Manual, at the following link: http://www.wipp.ws/library/t2omi/t2omi.htm.

\subsection{Annual Visual Inspections}

Tables 5.1 and 5.2 define the annual visual inspections to be performed on the ICV and OCA, respectively. General cleanliness should be observed for all components. Clean components with cloths or towels and denatured alcohol to enable proper visual inspection. Visual inspections shall determine that surfaces are free of excessive deformation, sliding surfaces do not have excessive wear, and threaded components are as specified and in good operating condition.

\subsection{Annual Dimensional Inspections}

Table 5.3 denotes the annual dimensional inspections to be performed on the ICV and OCA. General cleanliness should be observed for all components. Clean components with cloths or towels and denatured alcohol to enable proper dimensional inspection. Should components fail to meet the defined acceptance criteria following corrective action(s), prepare an NCR for disposition. All NCRs shall be dispositioned by the WIPP M\&O contractor.

\subsection{Annual ICV Interior Surfaces Inspection}

An annual inspection shall be performed on the ICV in accordance with Section 8 of the TRUPACT-II and HalfPACT SARP. If unacceptable indications are found, record the locations, make a photographic record, and submit an Approval Request/Variation Request (AR/VR) for disposition by the WIPP M\&O contractor.

Relevant indications shall be repaired in accordance with WI-CH.12.

When an annual inspection is performed in conjunction with a five-year structural pressure test, liquid penetrant examinations shall be conducted AFTER the structural pressure test to avoid duplication of effort.

\subsection{Five-Year Structural Pressure Tests}

Five-year structural pressure testing of the OCV and ICV shall be performed in accordance with Section 8 of the TRUPACT-II and HalfPACT SARP. Unacceptable indications of cracking or distortion shall be recorded for disposition by the WIPP M\&O contractor.

Upon successful completion of the preceding tests, periodic leakage rate testing shall be performed.

\subsection{Packaging Component Replacement Schedule}

Packaging components shall be replaced as defined in the schedule provided in Table 5.4, or when damage is noted. Should replacement of a given component fail to meet the acceptance criteria, an NCR shall be prepared for disposition by the WIPP $\mathrm{M} \& \mathrm{O}$ contractor. 


\subsection{Maintenance Records}

All maintenance performed on the $\mathrm{CH}$ packaging shall be documented on a maintenance record. Figure 5.1 is a sample of the maintenance record.

5.6.1 Instructions for completing the maintenance record:

- $\quad$ Packaging $S / \mathrm{N}$ - Record the serial number of the packaging.

- Date Initiated - Enter the date that the maintenance was initiated. (If no corrective actions are immediately performed, enter the date the discrepancy was discovered.)

- Location/Site - Enter the acronym for the site or location initiating the maintenance. (Example: INEEL, WIPP, EPD.)

- Job No. - Enter the next sequential job number from the site's packaging maintenance log. (See Section 5.7.)

- $\quad$ Reason for Maintenance - Check the appropriate block. Check other for unscheduled inspections, modifications, or repairs that are not listed in Attachment B.

- Discrepancy Description - Provide a short narrative description of repair or other discrepancies. No entry is required specifically for annual or five-year maintenance, but list discrepancies discovered as part of these scheduled inspections. List NCR numbers, tag numbers, or correspondence letter numbers, as applicable.

- Work Performed - Provide a concise description of the actions taken to correct discrepancies listed in the Discrepancy Description block. (Example: Replaced ICV upper main O-ring.)

- Work Instructions Used - List the work instruction numbers (example: WI-CH.10, WI-CH.11) used to perform the maintenance covered by the maintenance record.

- $\quad$ Measuring and Test Equipment (M\&TE) Used - List the M\&TE description, serial number (SN), calibration due date, and the work instructions.

- $\quad$ Spare Parts Used - List any spare parts that were used including description, part number, and WIPP purchase order (PO) number. (Required information is printed on packages.)

- Work Inspected by - Should be signed and dated by the supervisor of the personnel who performed the work. The signature verifies that the actions taken were within the scope of the work instructions or traveler (if applicable) and the packaging can be returned to service. This signature also indicates that the maintenance record is accurate and complete (i.e., all applicable supporting documentation is attached).

\subsubsection{Maintenance Record Disposition}

Upon completion of maintenance, the ORIGINAL CH packaging maintenance record, including attachments to the work instructions, shall be transmitted to the CH Packaging Maintenance Engineer, P.O. Box 2078, Carlsbad, NM 88221. 
These should arrive within 7 working days of job completion. A faxed copy or electronic submittal should be sent immediately after maintenance activities are completed.

\subsection{Maintenance Log}

Each user site shall maintain a packaging maintenance log. The log shall contain copies of completed maintenance records and a sequential listing, by job number, of maintenance performed on packaging. The user copies of maintenance records shall be kept for three years, after which they may be discarded.

\subsection{Maintenance Due Labels}

Upon completion of annual maintenance, the maintenance facility shall affix, adjacent to the packaging name plate, a maintenance due label indicating the month maintenance was performed. The packaging is considered Out-of-Service on the last day of the month indicated on this label (i.e., if annual maintenance is performed on September 15, 1999, the packaging may be used until September 30, 2000).

Upon completion of five-year maintenance, the maintenance facility shall affix, adjacent to the packaging name plate, a maintenance due label indicating the month maintenance was performed. The packaging is considered Out-of-Service on the last day of the month indicated on this label (i.e., if five-year maintenance was performed on September 15, 1999, the packaging may be used until September 30, 2004). 
Figure 5.1 - Maintenance Record

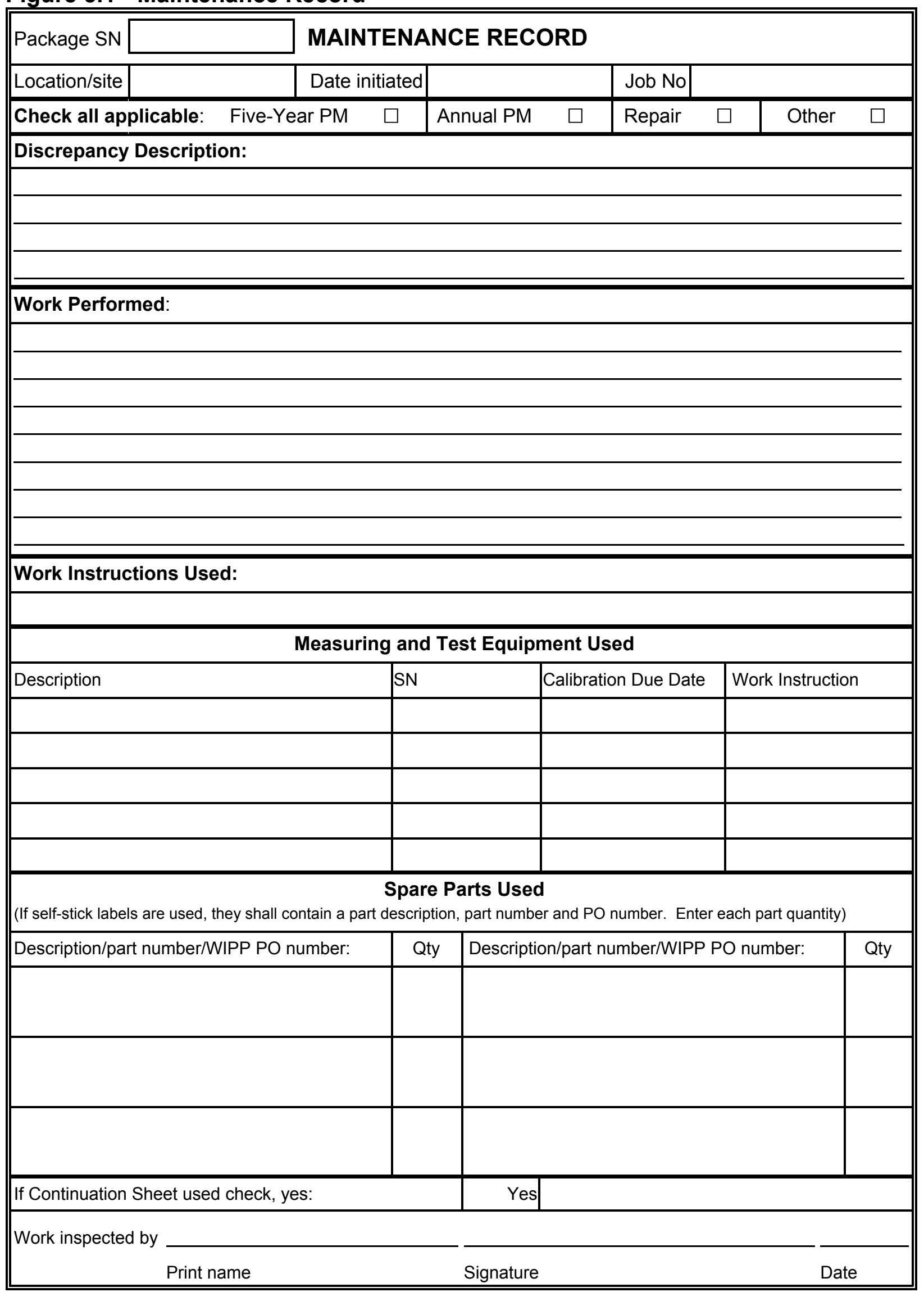


Figure 5.1 - Maintenance Record (continued)

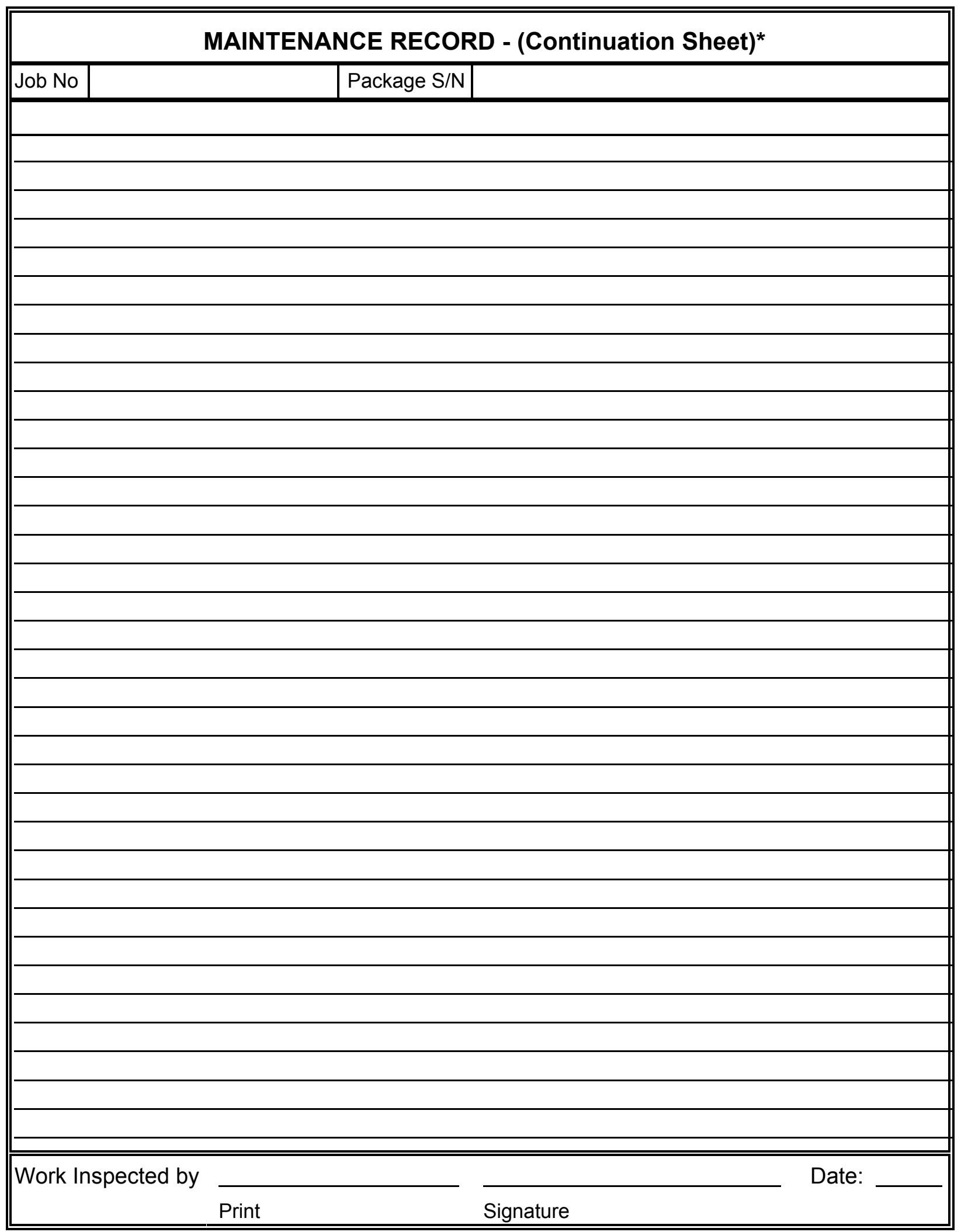

* If Continuation Sheet not used, discard. 


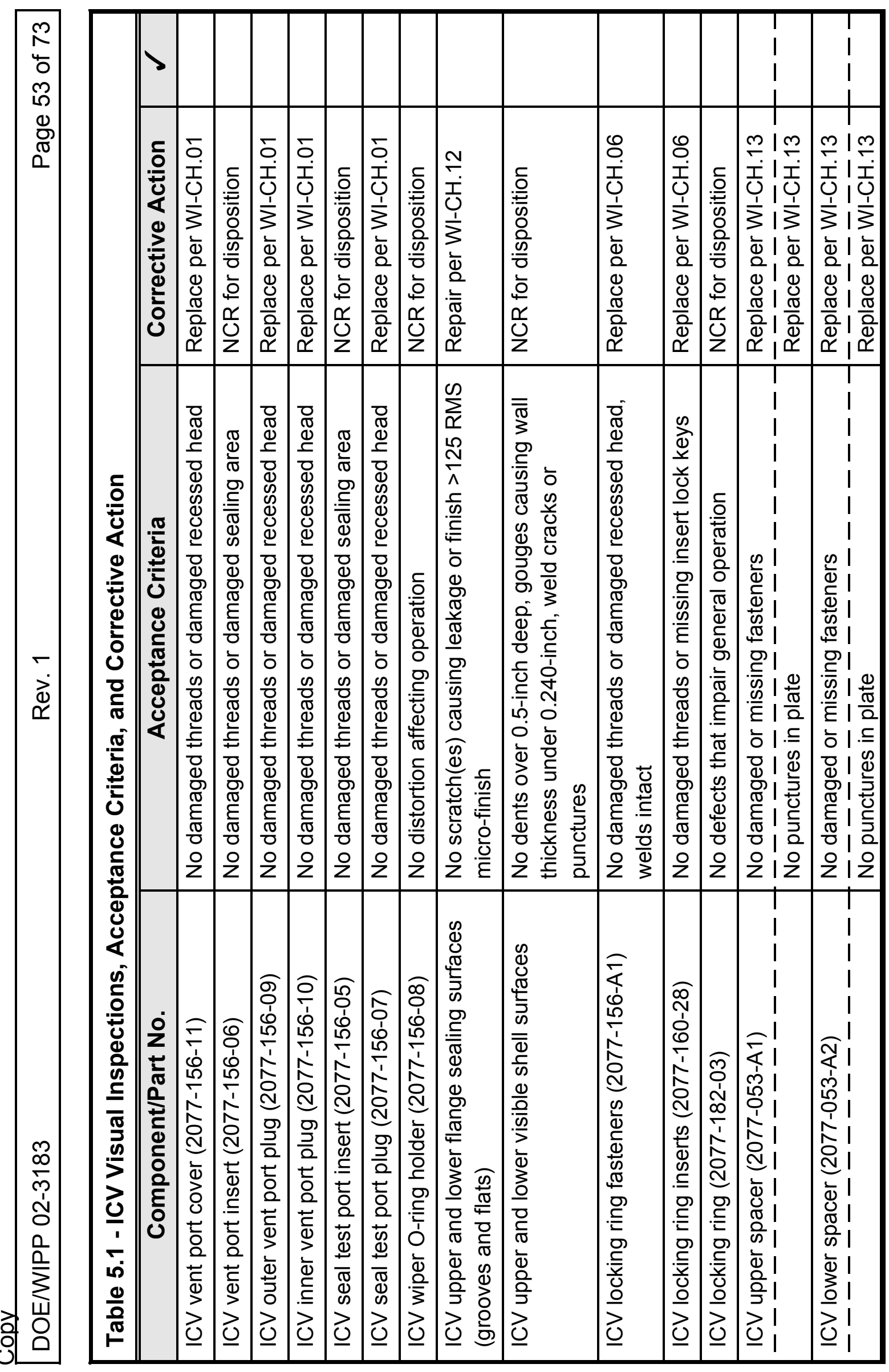




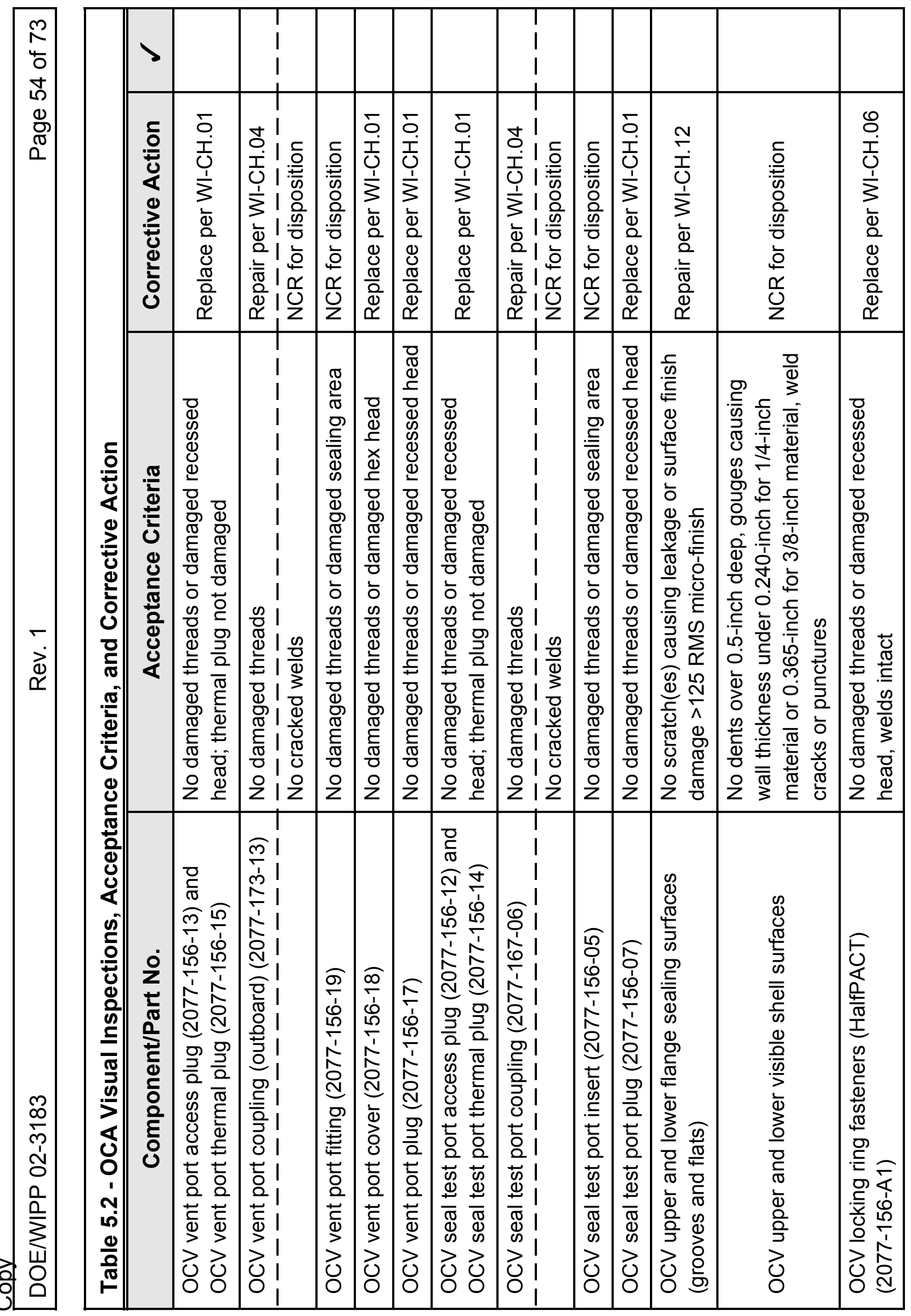




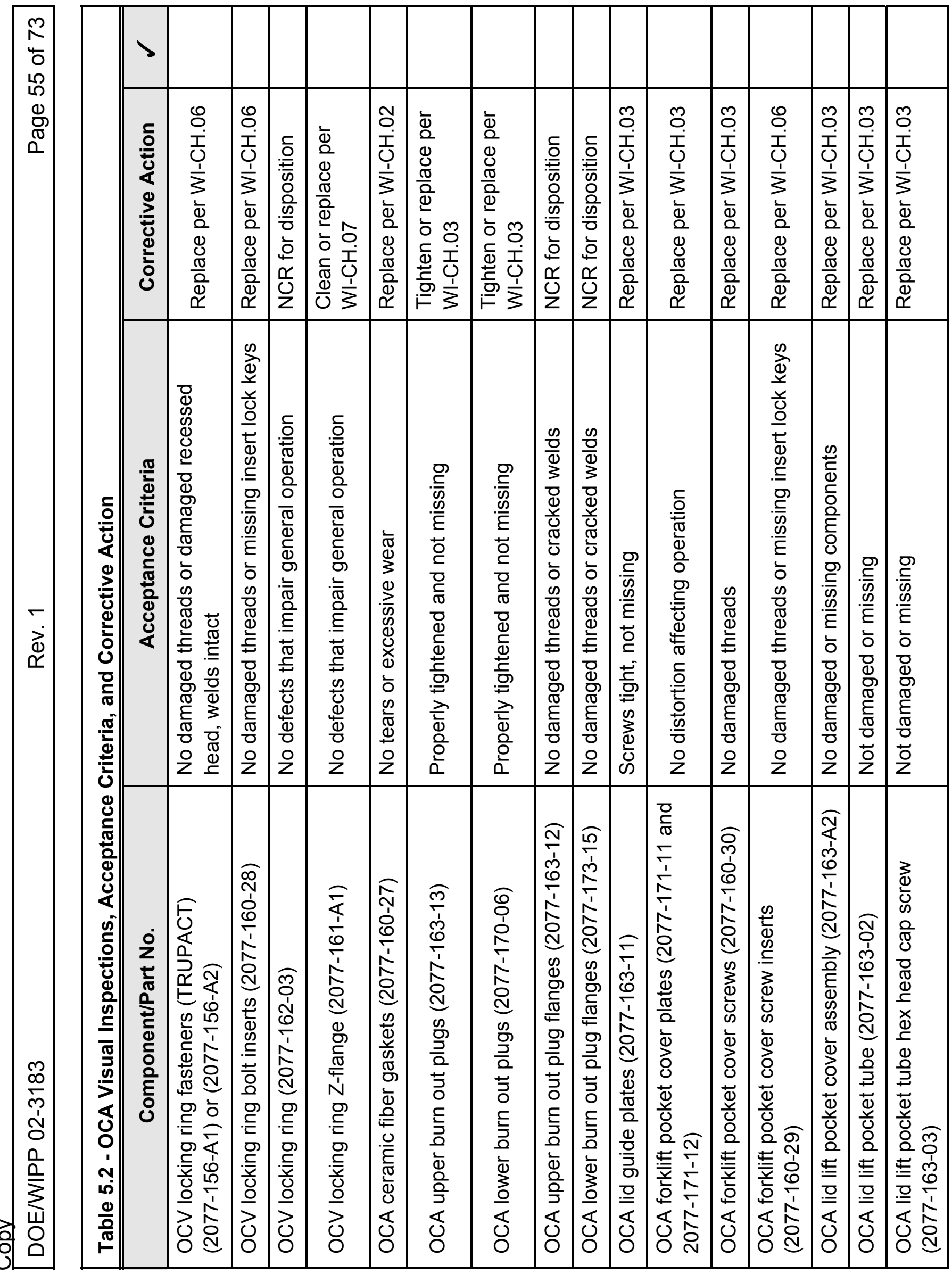




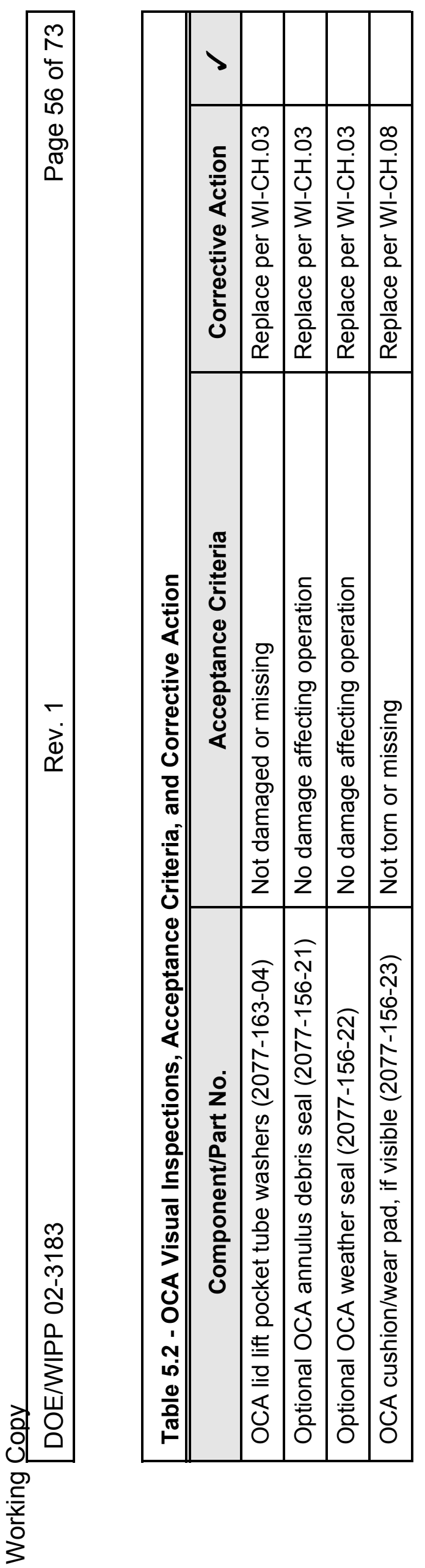




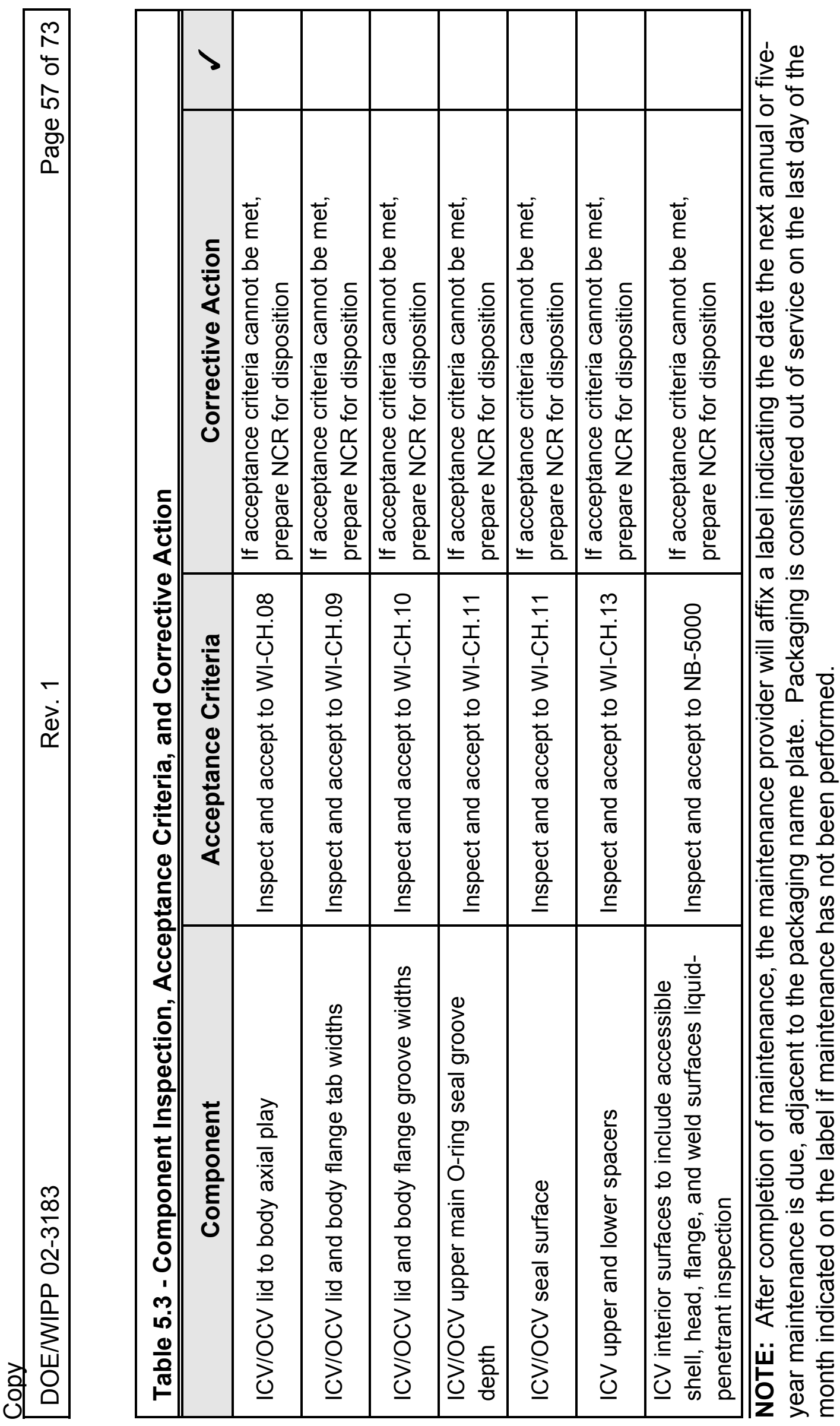




\begin{tabular}{||l|c|c|c||}
\hline \multicolumn{3}{|c|}{ Table 5.4 - Component Replacement Schedule and Work Instruction } \\
\hline \hline \multicolumn{1}{|c|}{ Component/Part No. } & Frequency & $\begin{array}{c}\text { Work } \\
\text { Instruction }\end{array}$ & $\checkmark$ \\
\hline \hline OCV upper main O-ring (2077-160-15) & Annual & WI-CH.02 & \\
\hline OCV lower main O-ring (2077-160-24) & Annual & WI-CH.02 & \\
\hline OCV seal test port plug O-ring (2077-160-26/180-24) & Annual & WI-CH.01 & \\
\hline OCV vent port plug seal O-ring (2077-160-17/180-22) & Annual & WI-CH.01 & \\
\hline OCV vent port cover O-ring (2077-160-16) & Annual & WI-CH.01 & \\
\hline ICV upper main O-ring (2077-180-09) & Annual & WI-CH.02 & \\
\hline ICV lower main O-ring (2077-180-19) & Annual & WI-CH.02 & \\
\hline ICV seal test port plug O-ring (2077-180-24/160-26) & Annual & WI-CH.01 & \\
\hline ICV outer vent port plug O-ring (2077-180-21) & Annual & WI-CH.01 & \\
\hline ICV inner vent port plug O-ring (2077-180-22/160-17) & Annual & WI-CH.01 & \\
\hline ICV vent port cover seal (2077-180-16 or 2077-180-16A) & Annual & WI-CH.01 & \\
\hline ICV wiper O-ring (2077-180-27) & Annual & WI-CH.02 & \\
\hline ICV lid debris seal (2077-180-25) & Annual & WI-CH.02 & \\
\hline OCV vent port plug handling O-ring (2077-160-18) & Annual & WI-CH.01 & \\
\hline OCV vent port cover handling O-ring (2077-160-19) & Annual & WI-CH.01 & \\
\hline \hline
\end{tabular}




\subsection{PACKAGE MAINTENANCE LEAKAGE RATE TESTING}

DOE/WIPP 02-3185, CH Packaging Maintenance Manual, for maintenance leakage rate testing is available on the internet at: http://www.wipp.ws/library/t2omi/t2omi.htm.

\subsection{PACKAGE STRUCTURAL PRESSURE TESTING}

DOE/WIPP 02-3185, CH Packaging Maintenance Manual, for structural pressure testing is available on the internet at: http://www.wipp.ws/library/t2omi/t2omi.htm. 


\section{Attachment A - Work Instruction Format}

\section{A.1 Preparing Work Instructions for Periodic Maintenance or Initial Release}

All packaging work/periodic maintenance instructions will be written using the following work instruction format. The following descriptions and examples will aid in writing work instructions.

- Title

A short description of the work or periodic maintenance to be performed.

- Approval Signatures

- Instruction Number

Assigned by the WIPP M\&O contractor. After the instruction number, enter the revision number.

- $\quad$ Packaging Serial Number

Insert the appropriate serial number at the time of performance.

- Page _ of _ _

Insert form page numbering information here.

- $\quad$ Applicable Drawings

Drawings that apply to the work instruction may be SARP drawings or additional shop drawings required to complete the task.

- $\quad$ SARP Requirements

A short narrative of the SARP requirement, referencing the appropriate SARP Chapter and/or section(s).

- $\quad$ Special Tools Required

List special tools required to complete the task.

- $\quad$ Spare Parts Required

List all packaging spare parts required to complete the task. 
- Materials Required

List all materials required to complete the task.

- $\quad$ Safety Requirements

List safety precautions needed to complete the task.

- $\quad$ Prerequisite Conditions

List any required prerequisite conditions.

- Instruction steps

List the detailed procedural steps to follow to complete the task.

- Verification Requirements

List the verification requirements (for example, leak tests, material certification) required to complete the test.

- $\quad$ Signature

Appropriate signatures shall be provided for all signature blocks.

\section{A.2 Revising Existing Work Instructions}

The revision will require the same approval as the original instruction. The user may initiate revisions by telephone or in writing to the WIPP M\&O contractor. The WIPP $M \& O$ contractor will approve tentative revisions by telephone, if necessary, and initiate the written revision.

The WIPP M\&O contractor can be reached during business hours at (505) 234-7500. After business hours, call the WIPP Central Monitoring Room (CMR) at (505) 234-8125/8457 for communication of relevant items.

\section{A.3 Cancellation of Existing Work Instructions}

Approvals for cancellation will be made by CBFO. A copy of the instruction shall be provided to the CBFO. The cancellation letter shall be attached to the original work instruction and dispositioned per DOE-CAO-94-1001, Information Management Plan. The canceled work instruction and all references to the canceled work instruction shall be deleted from this document through the normal change and revision procedure, and changes will be distributed to all user sites. 
Page 1 of 4

\begin{tabular}{||l|l||}
\hline \multicolumn{2}{|c||}{ WORK INSTRUCTION } \\
\hline \hline \multirow{2}{||}{ Title: } & Instruction No.: \\
\cline { 2 - 2 } & Page of \\
\hline Applicable Drawings: \\
\hline SARP Requirements: \\
\hline Special Tools Required: \\
\hline Spare Parts Required: \\
\hline Materials Required: \\
\hline Prerequisite Conditions: \\
\hline
\end{tabular}


Page 2 of 4

\begin{tabular}{||l||}
\hline \multicolumn{1}{|c||}{ WORK INSTRUCTION } \\
\hline \hline Instruction No. Continued \\
\hline Instruction Steps:
\end{tabular}


Page 3 of 4

\begin{tabular}{||l||}
\hline \multicolumn{1}{|c||}{ WORK INSTRUCTION } \\
\hline \hline Instruction No. Continued \\
\hline Instruction Steps Continued: \\
\hline \\
\hline
\end{tabular}


Page 4 of 4

\begin{tabular}{||ll||}
\hline \multicolumn{1}{|c|}{ WORK INSTRUCTION } \\
\hline \hline Instruction No. Continued & Page of \\
\hline Instruction Steps Continued: & \\
& \\
\hline Verification Requirements: & \\
\hline \hline Written by: & Date: \\
\hline Approved by: QA & Date: \\
\hline Approved by: Transportation Programs & Date: \\
\hline \hline
\end{tabular}


Attachment B - Approved Work Instructions

NOTE: All work instructions listed below can be performed by the maintenance vendor. Work Instructions WI-CH.01 through WI-CH.06, WI-CH.12, and WI-CH.14 are considered to be within the capabilities of a user to perform. Additionally, steps from WI-CH.08 that pertain to the adjustment of the wear pad, steps from WI-CH.13 that pertain to the replacement of spacer fasteners, washers and screws, and steps 8 and 9 of WI-CH.07 for installation of OCV locking Z-flange screws are considered within the capabilities of users to perform.

NOTE: Conditions may warrant that only specific steps of a work instruction are required for corrective action. Consequently, it is acceptable to perform only the necessary steps and to mark the ones not needed as NA.

- WI-CH.01, Replacement of ICV/OCV Small Plugs, O-rings, Gaskets

- WI-CH.02, Replacement of ICV/OCV Upper and Lower Main O-Rings, ICV Wiper O-ring, OCA Fiber Gasket and ICV Debris Seal

- WI-CH.03, Replacement of Miscellaneous Parts Not Requiring Detailed Instructions

- WI-CH.04, Cleaning Flange Threads for OCV Seal Test Port/Vent Port Access Covers

- WI-CH.05, Replacement of Polyethylene Filter in ICV Seal Flange

- WI-CH.06, Replacement of Threaded Inserts/Fasteners for Packaging

- WI-CH.07, Replacement of OCV Lock-Ring Actuator

- WI-CH.08, Axial Play Measurement (OCV Lid-to-Body) (ICV Lid-to-Body) and Wear Pad Replacement

- WI-CH.09, ICV/OCV Lid and Body Seal Flange Tab Widths

- WI-CH.10, ICV/OCV Lid and Body Flange Groove Widths

- WI-CH.11, ICV/OCV Upper Main O-Ring Seal Groove Depth Measurement and Surface Finish

- WI-CH.12, Minor Repair of Vessel O-ring Sealing Surface ICV/OCV, Minor Repair of Wall Surface ICV/OCA (Exposed Surfaces)

- WI-CH.13, Replacement/Inspection/Measurements ICV Honeycomb Spacers 
- WI-CH.14, Minor Repair of ICV/OCV O-Ring Locking Surfaces (burrs, dings, and nicks)

- WI-CH.15, Annual and Five-Year Maintenance Inspections

- WI-CH.16, Repair of ICV/OCV Locking Ring Stop Plate(s)

- WI-CH.17, Repair of ICV Upper/Lower Spacer Bracket(s)

- WI-CH.18, Repair of ICV Upper/Lower Honeycomb Spacer 
Attachment C - CH Packaging Qualification Requirements

The following guidelines establish the minimum training requirements for $\mathrm{CH}$ packaging operations. User site qualification cards SHALL include these items as a minimum. Users may separate the requirements to address different skills used to load a $\mathrm{CH}$ packaging per site requirements, as long as all areas are addressed by each site.

I. References

A. ADJUSTABLE CENTER OF GRAVITY LIFT FIXTURE

1. ACGLF Operation and Maintenance Manual

2. Drawing \#41-J-513 W

B. OPERATIONS

1. CH Packaging Program Guidance, DOE/WIPP 02-3183

2. $\mathrm{CH}$ Packaging SARP/HalfPACT SARP

3. DOE/WIPP Hoisting and Rigging Standard, DOE-STD-1090-99

C. MAINTENANCE

1. CH Packaging Program Guidance, DOE/WIPP 02-3183

2. TRUPACT-II SARP/HalfPACT SARP

D. TRAILER LOADING AND UNLOADING TRUPACT-II

1. $\quad \mathrm{CH}$ Packaging Program Guidance, DOE/WIPP 02-3183

2. TRUPACT-II SARP/HalfPACT SARP

3. DOE Hoisting and Rigging Standard, DOE-STD-1090-99

II. Knowledge

A. ACGLF

${ }^{1}$ This section applies only to those sites which remove the $\mathrm{CH}$ packagings from the trailer.

C - 1 
1. State the rated capacity of the ACGLF (ref. A.1, 2).

2. Describe the precaution that should be taken before the ACGLF is lifted without a load (ref. A.1, ACGLF Operating and Maintenance Instructions).

3. State what to look for when performing a preoperational check on the ACGLF (ref. A.1).

4. State what to inspect for on the SWB adapter (ref. A.1, ACGLF Operating and Maintenance Instructions).

5. State how to determine if lift clip assemblies are locked in the proper position (ref. A.1, ACGLF Operating and Maintenance Instructions).

\section{B. PACKAGING OPERATIONS}

1. Discuss the ICV/OCV lid removal process (ref. B.1).

2. Describe the purpose and identify the type of seals used on the packaging (ref. B.1, 2).

3. Describe the physical construction of the packaging assembly (ref. B.1, 2).

4. Describe the OCV Locking Ring Assembly (ref. B.1).

5. State the lubrication requirements for the O-ring seals (ref. B.1, 2).

6. Identify the tools required for packaging operation and discuss the function of each tool (ref. B.1, 2).

7. Explain the purpose of the following packaging components (ref. B.1, 2):
a. Seals
b. Lids
c. Pallet
d. Pick points
e. Closure ring lock points
f. Vent and test ports

8. Discuss the limits associated with packaging operations, i.e., pressure, radiation levels (ref. B.1, 2).

9. State the locations of the security seals (ref. B.1). 
10. Describe the precautions that should be taken when removing the OCV/ICV lids (ref. A.1, B.1, 2).

11. Describe the precautions that should be taken when installing the lids (ref. B.1).

12. Describe the precautions that should be taken when removing the ACGLF from the OCV/ICV lids and the waste packages (ref. A.1, B.1).

13. State the inspection process for the ICV and OCV (ref. B.1).

14. Describe the stuck lid removal process (ref. B.1).

\section{PACKAGING MAINTENANCE}

1. Describe the method of cleaning the port threads (ref. C.1).

2. Discuss the three different types of leak testing required for the packaging and when each must be performed (ref. C.1, 2).

3. Identify the materials needed to clean the sealing surfaces (ref. C.1).

4. State the hazards associated with improper drill depth setting when replacing threaded inserts (ref. C.1).

5. Identify materials required to replace ICV lid debris seal (ref. C.1).

6. State how to replace ICV lid debris seal (ref. C.1).

7. Describe how to complete a packaging maintenance record.

8. State the record retention requirement for packaging maintenance records.

\section{TRAILER LOADING AND UNLOADING ${ }^{2}$}

1. Describe the use and/or purpose of proper forktine position for handling packaging (ref. D.1, 2, 3).

2. Describe the process of removing the packaging from the trailer (ref. D.1, 3).

3. Discuss what is inspected on the trailer tie-down assembly (ref. D.1).

4. State how to re-work/clean tie-downs (ref. D.1).

${ }^{2}$ This section applies only to those sites which remove the $\mathrm{CH}$ packagings from trailer.

$$
\text { C - } 3
$$


5. State how to lubricate tie-downs (ref. D.1).

6. State the maximum load limit for the TRUPACT-II and HalfPACT trailer (ref. D.1, 2).

7. State the process of installing packaging tie-downs (ref. D.1).

III. Operations

A. ACGLF

1. Perform a preoperational check of the ACGLF (ref. A.1).

2. Operate ACGLF (ref. A.1, B.1, 3).

3. Perform standard waste box adaptor preoperational checks (ref. A.1).

4. Operate standard waste box adapter (ref. A.1, B.1, 3).

\section{B. PACKAGING OPERATION}

1. Perform OCV lid removal (ref. B.1, 3).

2. Perform ICV lid removal (ref. B.1, 3).

3. Load a standard waste box payload (ref. B.1, 3).

4. Load a drum payload (ref. B.1, 3).

5. Inspect OCV lid assembly (ref. B.1).

6. Inspect OCV lower assembly (ref. B.1).

7. Inspect ICV (ref. B.1).

8. Inspect ICV lower assembly (ref. B.1).

9. Perform ICV lid installation (ref. B.1).

10. Perform OCV lid installation (ref. B.1).

11. Prepare packaging for trailer loading (ref. B.1).

C. PACKAGING MAINTENANCE

1. Replace a small O-ring (ref. C.1).

2. Replace ICV/OCV locking ring bolt threaded inserts (ref. C.1).

3. Replace ICV lid debris seal (ref. C.1).

4. Complete maintenance record (ref. C.1).

$$
\text { C - } 4
$$


D. TRAILER LOADING AND UNLOADING

1. Transport a packaging from the trailer to a designated area (ref. D.1, 3).

2. Load a packaging on the trailer (ref. D.1, 3).

3. Install trailer tie-downs (ref. D.1).

4. Perform trailer tie-down assembly inspections (ref. D.1).

5. Unload a packaging from a trailer (ref. D.1, 3). 